\title{
Propofol Modulates Activation and Desensitization of GABA Receptors in Cultured Murine Hippocampal Neurons
}

\author{
Beverley A. Orser, ${ }^{1}$ Lu-Yang Wang, ${ }^{2}$ Peter S. Pennefather, ${ }^{2,3}$ and John F. MacDonald ${ }^{2}$ \\ 'Department of Anaesthesia, Sunnybrook Health Science Centre, Toronto, Ontario, Canada, and 'Departments of \\ Physiology and Pharmacology, ${ }^{3}$ Faculty of Pharmacy and Faculty of Medicine, University of Toronto, Toronto, Ontario, \\ M5S 1 A8 Canada
}

Propofol (2,6 di-isopropylphenol) is an alkyphenol recently introduced for use as a general anesthetic. The modulation of $\mathrm{GABA}_{\mathrm{A}}$ receptor activation and desensitization by propofol was studied using a rapid perfusion system and wholecell voltage-clamp recordings from mouse hippocampal neurons. The effects of concentrations of propofol used clinically on single-channel and synaptic currents were also examined. Propofol evoked current responses $\left(E C_{50}=61 \mu \mathrm{M}\right)$ and shifted the dose-response curve of GABA-activated current to the left without altering the maximum of the GABA response. Preincubation with propofol and GABA led to desensitization of the GABA response $\left(E_{50}=454 \mu \mathrm{M}\right.$ and 23 $\mu \mathrm{M}$, respectively). Saturating concentrations of GABA (600 $\mu \mathrm{M})$ evoked currents that peaked and then declined in a biexponential fashion with fast and slow time constants of $\tau_{f}=1.0 \mathrm{sec}$ and $\tau_{\mathrm{s}}=3.5 \mathrm{sec}$. Propofol $(10 \mu \mathrm{m})$ did not change the amplitude of the peak response but decreased the rates of decay approximately 1.5 -fold and enhanced the steadystate current proportionately. Recovery from desensitization was also biexponential $\left(\tau_{f}=11 \mathrm{sec}, \tau_{\mathrm{s}}=69 \mathrm{sec}\right)$ but not influenced by propofol. Single-channel recordings from outside-out patches demonstrated that both propofol and GABA activated channels with a $30 \mathrm{pS}$ and 21 pS open state. Propofol increased the frequency but not the duration or conductance of GABA-activated events. Miniature inhibitory postsynaptic currents (mIPSCs) were evoked by the application of hypertonic sucrose to the cell soma. Propofol $(2$ $\mu \mathrm{M})$ prolonged the decay time of mIPSCs to an extent similar to which it increased the open probability of GABA-activated channels (2.3- vs 3-fold). A sequential model, based on a previous scheme of GABA receptor gating (Weiss and Magelby, 1989), is presented to summarize propofol's actions on $\mathrm{GABA}_{\mathrm{A}}$ receptor function. We show through simulation that the model reliably reproduced the whole-cell tracings. Our results indicate that propofol's neurodepressive actions will be associated with enhancement of inhibitory synaptic transmission.

[Key words: propofol, 2,6 di-isopropylphenol, GABA, desensitization, patch clamp, anesthetics]

Received Apr. 1, 1994; revised June 6, 1994; accepted June 8, 1994.

This work was supported by a grant to J.F.M. and the Medical Research Council of Canada Group "Nerve Cells and Synapses." B.A.O. is a fellow of the Medical Research Council of Canada. We thank Ms. C. Bartlett and L. Brandes for technical assistance.

Correspondence should be addressed to Dr. B. Orser, Department of Physiology, University of Toronto, 1 King's College Circle, Toronto, Ontario, Canada M5S $1 \mathrm{~A} 8$.

Copyright (C) 1994 Society for Neuroscience $0270-6474 / 94 / 147747-14 \$ 05.00 / 0$
GABA, the major inhibitory neurotransmitter in the mammalian brain, activates at least two distinct types of receptors (for review, see Sivilotte and Nistri, 1991). The GABA $\mathrm{A}_{\mathrm{A}}$ receptor is composed of several protein subunits that incorporate $\mathrm{Cl}^{-}$selective ion channel whereas $\mathrm{GABA}_{\mathrm{B}}$ receptors are single subunits that couple to G-proteins and thereby modulate $\mathrm{K}^{+}$and $\mathrm{Ca}^{2+}$ channels. The $\mathrm{GABA}_{\mathrm{A}}$ class of receptors mediate fast neurotransmission in the majority of inhibitory synapses.

The $\mathrm{GABA}_{\mathrm{A}}$ receptor is thought to be the site of action for a variety of drugs with hypnotic, anesthetic, and anticonvulsant properties (Sieghart, 1992). Propofol, sedative benzodiazepines, barbiturates, alphaxalone, and several neuroactive steroids bind to distinct sites on GABA receptors and enhance GABA-activated $\mathrm{Cl}^{-}$flux (Barker et al., 1987; Vicini et al., 1987; Collins, 1988; Macdonald et al., 1989; Robertson, 1989; Concas et al., 1991; Hales and Lambert, 1992; I Iara et al., 1993). The mechanisms by which these drugs influence $\mathrm{GABA}_{\mathrm{A}}$ channel activation are not well understood. Anesthetics may alter agonist binding, receptor-channel coupling or directly modulate channel gating, and different concentrations of a drug may influence receptor/channel behavior differently. For example, the benzodiazepine flunitrazepam enhances GABA binding and increases the frequency of GABA-activated channel opening. Flunitrazepam does not, however, directly activate the channel or alter the mean duration of open events (Vinici et al., 1987). In contrast, pentobarbitone, alphaxalone, and some neuroactive steroids activate channel opening in the absence of exogenous GABA and increase the mean open time of the channel (Barker et al., 1987; Macdonald et al., 1989; Mienville and Vicini, 1989; Twyman and Macdonald, 1992). Similarly, propofol alone increases $\mathrm{Cl}^{-}$conductance and increases the open probability of GABA-activated channcls (Halcs and Lambert, 1992). It has not previously been determined if propofol increases the frequency or the duration of open events.

The efficacy of GABA-induced currents is also influenced by receptor desensitization (Frosch et al., 1992; Oh and Dichter, 1992). $\mathrm{GABA}_{\mathrm{A}}$ receptor desensitization is influenced by a variety of factors including agonist concentration, membrane potential, the developmental stage of the cell, and drugs (Mierlak and Farb, 1988; Wiess, 1988; Frosch et al., 1992; Oh and Dichter, 1992). Ligands other than GABA can also "cross-desensitize" the receptor. Recently it was reported that preincubation with GABA reduced the response to a subsequent application of propofol (Hara et al., 1993). It is therefore likely that propofol can "cross-desensitize" GABA-mediated responses. The concentration dependence of propofol-induced desensitization of $\mathrm{GABA}_{\mathrm{A}}$ receptors is of clinical interest as it has been suggested 
that neuroexcitation observed during propofol anesthesia may result from $\mathrm{GABA}_{\mathrm{A}}$ receptor desensitization and disinhibition (Hara et al., 1993; Ries et al., 1994).

The purpose of this study was to investigate the effects of a wide range of concentrations of propofol (1-10,000 $\mu \mathrm{M})$ on GA$\mathrm{BA}_{\mathrm{A}}$ receptor activation and desensitization by examining wholecell currents recorded from mouse hippocampal neurons. We also examined the effects of low, clinically effective concentrations of propofol (0.5-2 $\mu \mathrm{M})$ on single-channel events and synaptic currents. We report that propofol influenced $\mathrm{GABA}_{\mathrm{A}}$ receptor function in three ways: low concentrations $(2-100 \mu \mathrm{M})$ potentiated GABA-activated currents, increased the frequency of opening of GABA channels, and reduced the rate of desensitization; intermediate concentrations $(10-1000 \mu \mathrm{M})$ of propofol directly activated $\mathrm{GABA}_{\mathrm{A}}$ channels and induced receptor desensitization; the third action, apparent at high concentrations (600-10,000 $\mu \mathrm{M})$, was to inhibit receptor/channel function presumably by a noncompetitive blocking action. To summarize these findings we present a sequential model of channel gating by GABA and propofol that incorporates the modulating and direct blocking effects of propofol on $\mathrm{GABA}_{\mathrm{A}}$ receptor function.

Preliminary results have appeared in an abstract form (Orser et al., 1993a,b).

\section{Materials and Methods}

Cell culture. Cultures of embryonic hippocampal neurons were prepared from Swiss White mice as previously described (MacDonald et al., 1989). Fetal hippocampi were obtained from mice killed by cervical dislocation. Neurons were dissociated using enzymatic digestion and mechanical trituration and plated at a density of $1 \times 10^{6} / \mathrm{mm}^{2}$ on 35 $\mathrm{mm}$ collagen-coated culture dishes. Monolayers of cells were used following $10-14 \mathrm{~d}$ in culture. Prior to recording, cells were rinsed with a standard extracellular recording solution containing (mM) $140 \mathrm{NaCl}$, $1.3 \mathrm{CaCl}_{2}, 5.4 \mathrm{KCl}, 25 \mathrm{~N}$-2-hydroxy-cthylpipcrazine- $N^{\prime}$-2-ethanesulfonic acid (HEPES), 33 glucose, and $300 \mathrm{~nm}$ tetrodotoxin, with pH adjusted to 7.4 with $\mathrm{NaOH}$.

Recording techniques and drug application. Whole-cell patch electrodes, with a resistance of 3-10 M $\Omega$, were constructed from borosilicate glass capillaries containing an inner filament (World Precision Instruments). Electrodes were pulled in two stages using a vertical puller (Narishige P-83) and filled with a solution containing (mM) $140 \mathrm{CsCl}$ or choline $\mathrm{Cl}, 10 \mathrm{HEPES}, 11 \mathrm{EGTA}$, and $1 \mathrm{CaCl}_{2}$, adjusted to a $\mathrm{pH}$ of 7.4 with $\mathrm{CsOH}$. For most experiments, a support solution containing (mM) 2 TEA, $2 \mathrm{MgCl}_{2}, 4$ Tris-ATP, 20 phosphocreatine, and $50 \mathrm{U} \mathrm{ml}^{-1}$ creatine phosphokinase was added to the recording solution to retard the "rundown" of currents (Forscher and Oxford, 1985). Cells were voltage-clamped using a patch-clamp amplifier (Axopatch 1B, Axon Instruments Inc.) and currents were simultaneously recorded on a pen recorder (Gould Inc.) and PC computer using the pCLAMP program (Axon Instruments, Inc.) or Strathclyde Electrophysiological Software (courtesy of Dr. J. Dempster, Strathclyde University). All experiments were conducted at room temperature $\left(20-25^{\circ} \mathrm{C}\right)$. Drugs were applied to the cells using a multibarrel fast-perfusion system. During recordings, solutions were continuously pumped through the barrels using a roller pump (Ismatec Pump, Cole-Palmer) and barrel position was controlled by a computer-driven DC stepping motor (Vexta, Oriental Motor Co. Ltd.) The speed of the fast perfusion system $(<30 \mathrm{msec})$ was estimated from the rate of onset of $\mathrm{Mg}^{2+}$-induced inhibition of NMDA currents recorded at hyperpolarizing potentials.

For concentration-response analysis, data were plotted using sIGMAPLOT (Jandel Scientific) and fitted with a standard logistic equation in the form $l=I_{\max } /\left(1+C / \mathrm{EC}_{50}\right)^{n}$, where $I$ represents the predictcd current amplitude at a given concentration of agonist, $I_{\max }$ is the response to saturating concentrations of agonist, $C$ is the agonist concentration, $\mathrm{EC}_{50}$ is the agonist concentration that produces $50 \%$ of the maximal response, and $n$ is the estimated Hill coefficient. Data are represented as the mean \pm SEM for cells unless otherwise indicated.

Miniature inhibitory postsynaptic currents (mIPSCs). Miniature inhibitory postsynaptic currents were repetitively evoked by applying hy- pertonic sucrose solution (extracellular solution plus $0.25 \mathrm{~m}$ sucrose) to the cell soma (see Bekkers and Stevens, 1989). Experiments were performed in the presence of $\mathrm{Mg}^{2+}(2 \mathrm{mM})$ to reduce the spontaneous release of transmitters and to inhibit NMDA receptors. In addition, CNQX $(10 \mu \mathrm{M})$ was added to inhibit non-NMDA receptor-mediated excitatory synaptic currents. The amplitudes of the mIPSCs were constant over the experimental period and currents were abolished following the addition of bicuculline methiodide $(10 \mu \mathrm{M})$ to the bath. Synaptic currents were detected, averaged and fitted using an event detection program (sCAN, Strathclyde software program). For detection, a trigger level was set at approximately three times higher than the baseline noise. The decay phase of the mIPSCs was fitted using a biexponential equation in the form $I(t)=A_{f} \exp \left(-t / \tau_{f}\right)+A_{s} \exp \left(-t / \tau_{s}\right)+c$, where $I(t)$ is the current amplitude at any given time $t, c$ is the baseline current, $\tau_{f}$ and $\tau_{s}$ are the fast and slow time constants of current decay, respectively, and $A_{f}$ and $A_{s}$ are the estimated fast and slow intercepts of the components at time zero.

Single-channel recording technique. Single-channel recording electrodes (6-10 M $\Omega$ ) were coated with Sylgard (Dow Corning Corp.) and filled with a solution containing (mM) choline $\mathrm{Cl}, 140 ; \mathrm{CaCl}_{2}, 1 ; \mathrm{MgCl}_{2}$, 2; EGTA, 11; HEPES, 10; and TEA, 10; pH 7.38. Outside-out patches were obtained as previously described and voltage clamped (Hamill et al., 1981). Patches were positioned into the outflow from one of the perfusion barrels and the composition of the extracellular solution changed by moving the patch electrode. The extracellular perfusate contained (in mM) choline $\mathrm{Cl}, 140 ; \mathrm{CaCl}_{2}, 1 ; \mathrm{MgCl}_{2}, 2 ; \mathrm{HEPES}, 10$; glucose, 30; tetrodotoxin, $300 \mathrm{nM}$; with or without $2 \mu \mathrm{M} \mathrm{GABA}, 2 \mu \mathrm{M}$ propofol, or $2 \mu \mathrm{M}$ GABA plus $2 \mu \mathrm{M}$ propofol. Signals were filtered at 2 $\mathrm{kHz}(-3 \mathrm{~dB})$ with a low-pass 4-pole Bessel filter, digitized $(37 \mathrm{kH} /, 94.4$ kilosamples/sec, 14 bits), and recorded onto a VHS tape for off-line analysis with a PC computer. Current records were sampled at $100 \mathrm{sec}$ per point and analyzed using the FETCHAN program (pCLAMP, Axon Instruments). The amplitude of single-channel events was measured using two methods that produced similar results. Sampled data were displayed and the amplitude of currents measured by manually placing cursors at the open and closed current level. The amplitudes of multiple events were averaged to provide a mean single-channel amplitude. Alternatively, the threshold crossing method was used to measure the amplitude and duration of events. Amplitude histograms were constructed and fitted using the least-squares method for a Gaussian distribution. Single-channel slope conductance and reversal potentials were estimated from the current-voltage plots. Conductance was estimated from the slope of the regression line, calculated by a least-squares method. Only records that contained infrequent double openings ( $<5 \%$ of open events) were used for kinetic analysis. Although infrequent transitions to at least one subconductance state of approximately $21 \mathrm{pS}$ were observed, only events associated with the main open state were used for kinetic analysis. Events with a duration less than $300 \mathrm{sec}$ were ignored and no compensation was applied for undetected closed and open events (Twyman and Macdonald, 1992). Data were binned into frequency histograms and the estimates of time constants were obtained by fitting a biexponential function to the histograms using a nonlinear least-squares method. The binning parameters were identical for all open frequency histograms obtaincd under the various recording conditions.

Simulation. The implications of kinetic schemes to account for the data were examined using a general simulator program called AxON ENGINEER (Aeon Software, Eugene, OR). This program allows kinetic states to be defined and linked together by rate constants that can be a function of voltage, ion and drug concentration. The differential equations implicit in the kinetic scheme are then integrated and driven by user-defined stimuli. The distribution of states in time is converted to current by assigning conductance weights to the individual states and summating the system at each time point. The estimated conductance is then converted to current by making assumptions about the density and permeability properties of the conducting units.

Drugs and other chemicals. Propofol was prepared from Diprivan (ICI Pharm., Mississauga, Canada). Each milliliter of Diprivan contains 2,6 di-isopropylphenol, $10 \mathrm{mg}$; soybcan oil, $100 \mathrm{mg}$; egg lecithin, 12 $\mathrm{mg}$; and glycerol, $22.5 \mathrm{mg}$. Propofol stock $\left(10^{-2} \mathrm{M}\right)$ was prepared on the day of the experiment. Vehicle solution was prepared from Intralipid, 10\% (KabiVitrum Canada Inc., Toronto, Canada). Each milliliter of Intralipid contained soybean oil, $100 \mathrm{mg}$; egg lecithin, $12 \mathrm{mg}$; and glycerol, $22.5 \mathrm{mg}$; with $\mathrm{pH}$ adjusted to 7.2 with $\mathrm{NaOH}$. Unless specified otherwise, all other compounds were purchased from Sigma Chemical Co. (St. Louis, MO). 

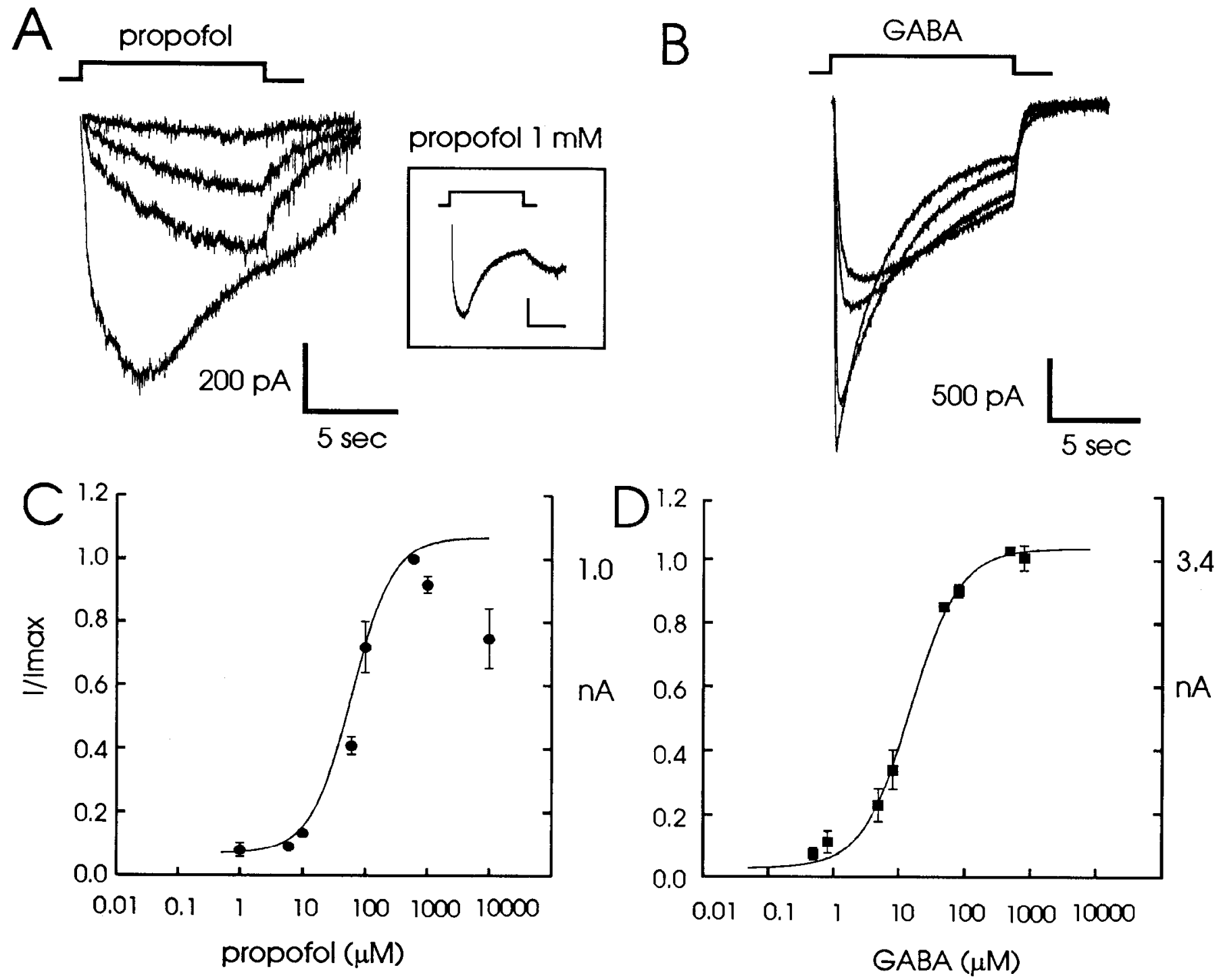

Figure 1. The effects of propofol and GABA on current responses in hippocampal neurons. The trace in $A$ illustrates currents of increasing amplitude, following the applications of propofol $(10,60,100,600 \mu \mathrm{M})$. Currents had a slow rate of onset and decayed during prolonged drug applications. The line at the top of the tracings indicates the duration of agonist perfusion. The inset illustrates a typical response observed during applications of concentrations of propofol (in this case $1 \mathrm{mM}$ ) greater than $600 \mu \mathrm{M}$. The calibration markers of the inset are equivalent to those in the main figure. Note the afterresponse that was evident following the switch to the control solution. $B$, GABA-evoked currents recorded from the same cell as the trace in $A$. The rapid onset of currents in response to GABA $(6,10,60,600 \mu \mathrm{M})$ is shown. $C$, Propofol activated inward currents as a function of propofol concentration. The propofol concentration-response curve is shown $(n=9$ cells). Fitting the Hill equation to concentrations of propofol ranging from 1 to $600 \mu \mathrm{M}$ provided an approximate $\mathrm{EC}_{50}$ value and Hill coefficient of $61 \mu \mathrm{M}$ and 1.3 , respectively. The right abscissa indicates the mean current amplitude. The dose-response curve for GABA-activated currents is illustrated in $D(n=8$ cells). The apparent EC 50 value and Hill coefficient were $19 \mu \mathrm{M}$ and 1.2 , respectively.

\section{Results}

Propofol activates $G A B A_{A}$ receptors and potentiates $G A B A$ evoked responses

Propofol $(10-1000 \mu \mathrm{M})$ induced inward currents in all $(n=27)$ hippocampal neurons tested. An example of this action is illustrated in Figure $1 \mathrm{~A}$. The threshold concentration for activation of this current was approximately 6-10 $\mu \mathrm{M}$. Maximal currents were observed at $600 \mu \mathrm{M}$; higher concentrations evoked progressively smaller currents (Fig. 1C). Upon the cessation of the application of a high concentrations of propofol $(>600 \mu \mathrm{M})$, a transient increase in current, which we refer to as an "afterresponsc," was observed (Fig. $1 \mathrm{~A}$, inset). In contrast, the peak response to saturating concentrations of GABA was constant and no secondary increase in current was observed during washout of the drug (Fig. 1B). Propofol and GABA currents had maximum amplitudes of $1.0 \pm 0.2 \mathrm{nA}(n=9)$ and $3.4 \pm 1.0$ $\mathrm{nA}(n=8)$, respectively. In three cells, where the maximum responses to both GABA and propofol were determined, the maximal current cvoked by propofol was $31.1 \pm 0.1 \%$ of that evoked by $\mathrm{GABA}$. The $\mathrm{EC}_{50}$ values for peak currents in response to GABA and propofol were calculated from the dose-response relationships and estimated to be $19 \mu \mathrm{M}$ and $61 \mu \mathrm{M}$, respectively (Fig. 1C,D).

The currents activated by propofol could have resulted from the potentiation of the response to tonically released GABA (Valeyev et al., 1993). We therefore examined the effects of flurazepam, a sedative benzodiazepine with minimal intrinsic 

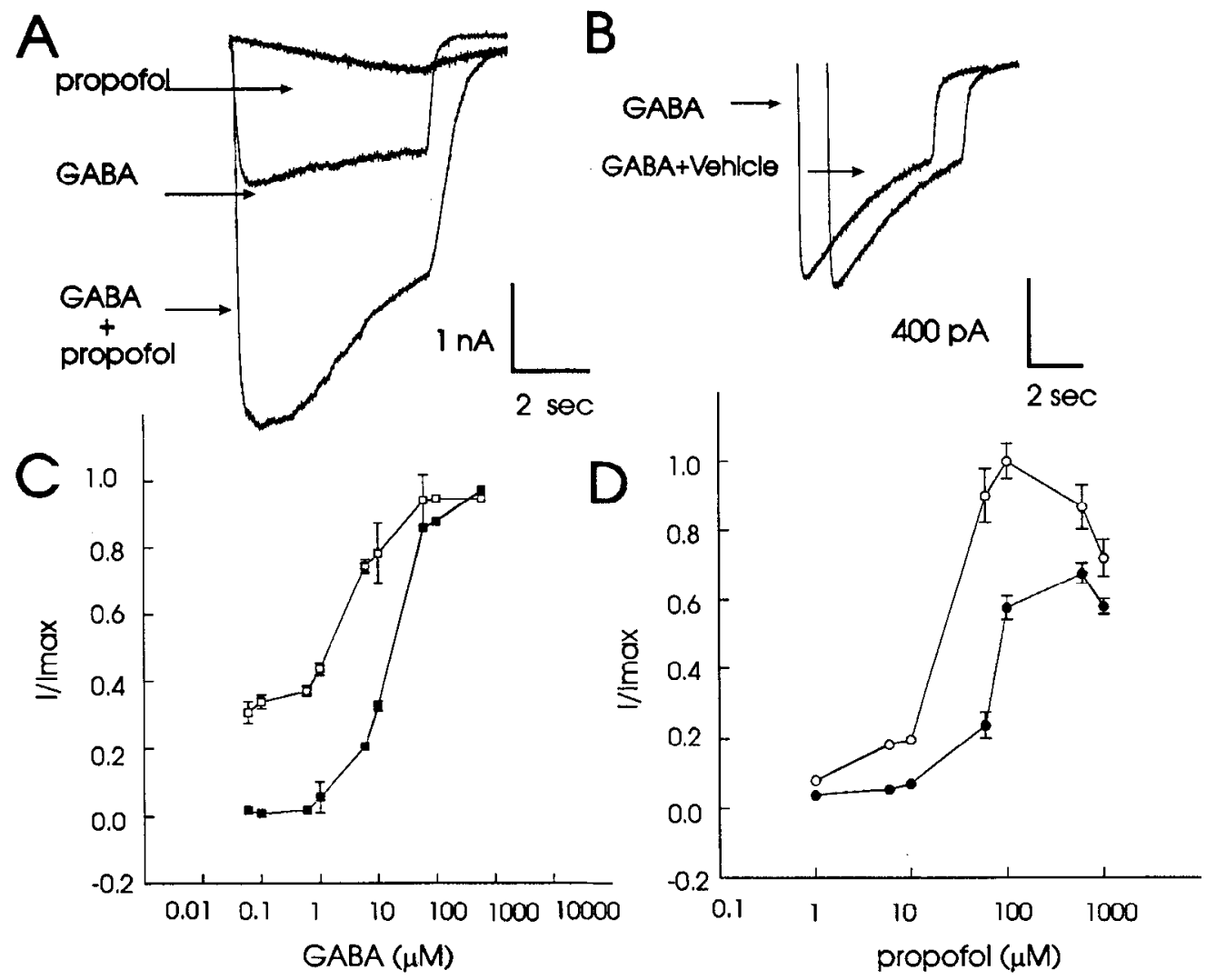

Figure 2. The effects of propofol on GABA-activated current in hippocampal neurons. $A$, The raw data tracings represent currents activated by propofol, $50 \mu \mathrm{M}$; GABA, $5 \mu \mathrm{M}$; and the combination of $50 \mu \mathrm{M}$ propofol and $5 \mu \mathrm{M}$ GABA. $B$, The vehicle solution, at a concentration equivalent to that present in propofol at $1 \mathrm{~mm}$, failed to increase the amplitude of peak or steady-state currents activated by GABA (100 $\mu \mathrm{M})$. $C$, The doseresponse curve for peak currents activated by various concentrations of GABA alone $(\square)$ or in combination with propofol $50 \mu \mathrm{M}(\square)(n=6)$. Propofol shifted the GABA response curve to the left but did not change the amplitude of the maximal response. $D$, The dose-response curve for peak current activated by propofol alone $(\odot)$ was shifted to the left by the addition of GABA $(2 \mu \mathrm{M})(\mathrm{O})$, and the maximal peak current was also increased. Data were averaged from three cells and normalized to maximal current activated by propofol and GABA.

GABA-mimetic properties, on our cultured neurons. Flurazepam $(10 \mu \mathrm{M})$ potentiated responses to exogenously applied GABA ( $2 \mu \mathrm{M})$ but failed to evoke currents on its own. The GABA receptor antagonist bicuculline $(10-100 \mu \mathrm{M})$ reversibly depressed propofol-activated currents whereas the glycine receptor antagonist strychnine (200 nM) had a minimal effect.

Intralipid, at concentrations equivalent to those used to emulsify propofol $(10 \mu \mathrm{M}$ to $1 \mathrm{mM})$, did not substantially potentiate or inhibit currents evoked by GABA nor did it evoke current on its own (Fig. $2 B$ ). In addition, increasing the concentration of Intralipid two- to fivefold had no effect of responses activated by propofol $(100 \mu \mathrm{M})$. It seems likely, therefore, that currents evoked by propofol are mediated by $\mathrm{GABA}_{\Lambda}$ receptors and are not an artifact of the Intralipid vehicle.

Responses to submaximal concentrations of GABA were increased by propofol $(0.1-1000 \mu \mathrm{M})$. These currents were larger than the sum of those activated by either propofol or GABA alone (Fig. 2A). This action was apparent in the dose-response relationship for GABA-activated currents (Fig. 2C). Propofol $(50 \mu \mathrm{M})$ shifted the GABA dose-response curve to the left but did not change the maximal response. Similarly, $2 \mu \mathrm{M}$ GABA shifted the propofol dose-response curve to the left along the propofol concentration axis (Fig. $2 D$ ). Note that with high concentrations of propofol, responses were less than those seen with lower concentrations in the presence and absence of GABA.
To determine if currents were primarily mediated by the outward movement of $\mathrm{Cl}^{-}$, the reversal potentials of currents activated by GABA, propofol, or GABA and propofol were examined under several conditions. With similar concentrations of $\mathrm{Cl}^{-}$in the recording pipette $(\mathrm{CsCl}$ or choline $\mathrm{Cl}, 140 \mathrm{~mm})$ and in the bathing solution ( $\mathrm{NaCl}, 140 \mathrm{mM})$, currents reversed polarity close to zero $\mathrm{mV}$ (Fig. $3 A$ ). Substitution of much of the $\mathrm{Cl}^{-}$in the recording pipette (in mM: $\mathrm{Cs}_{2} \mathrm{SO}_{4}, 90$; $\mathrm{CsCl}, 30$; HEPES, 10; EGTA, 11; $\mathrm{CaCl}_{2}, 1 ; \mathrm{MgCl}_{2}$, 2; TEA, 1) shifted the reversal potentials for currents induced by GABA, propofol, or the combination of GABA and propofol to $-25 \mathrm{mV}$, again close to the $\mathrm{Cl}^{-}$equilibrium potential. This observation suggest that currents are mediated primarily by an increase in $\mathrm{Cl}^{-}$conductance.

\section{Effects of propofol on desensitization of $G A B A_{A}$ receptors}

To examine the effects of propofol on desensitization of GABA $A_{A}$ receptors, we employed an application protocol similar to that described by Sather et al. (1992). The degree of desensitization produced by a conditioning application of GABA or propofol was estimated from the fractional reduction in the response to a subsequent test application of a saturating concentration of GABA. An example of this predesensitization protocol is illustrated in Figure $4 A$. Various concentrations of propofol $(6 \mu \mathrm{M}$ to $1 \mathrm{mM})$ or GABA $(0.6 \mu \mathrm{M}$ to $600 \mu \mathrm{M})$ were used for the conditioning applications. Prior to each conditioning application, 


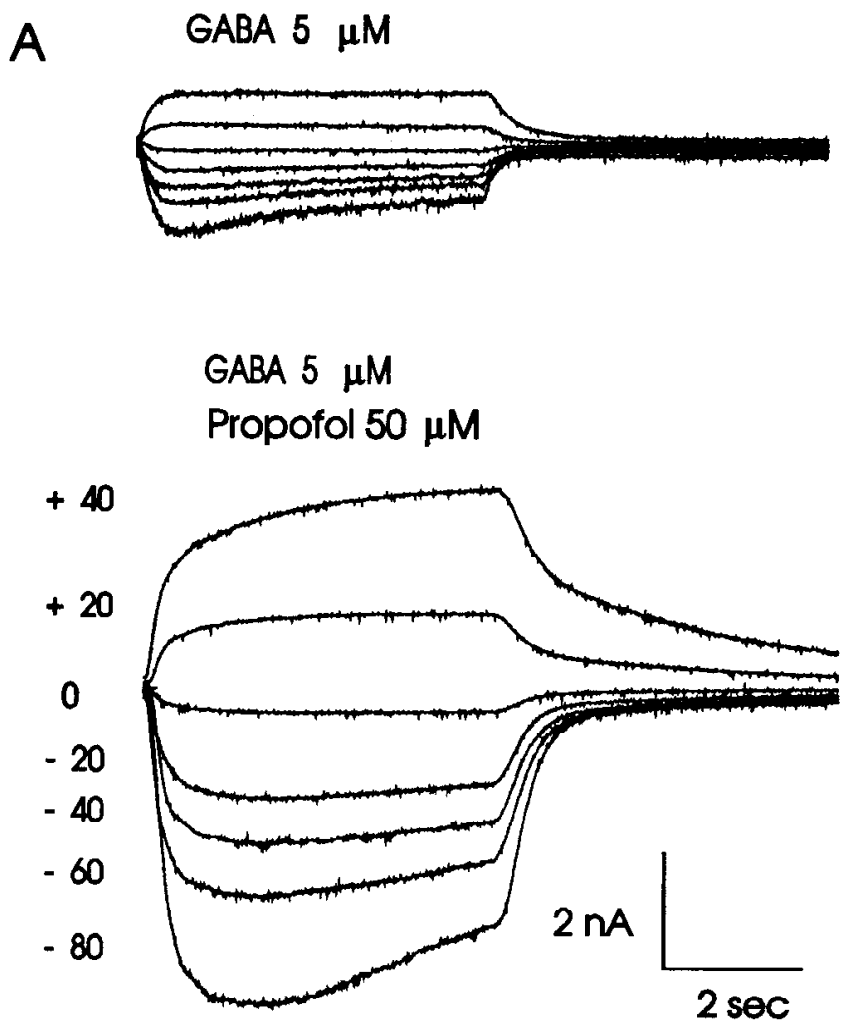

Propofol $600 \mu \mathrm{M}$

B

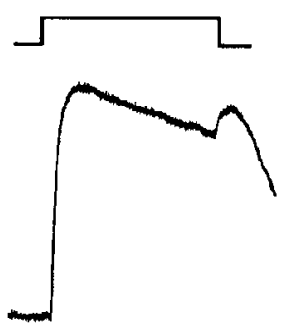

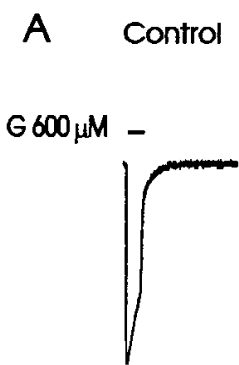

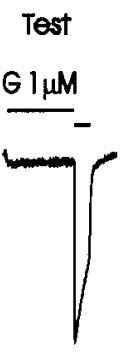

Control Test

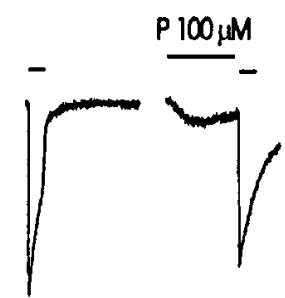

$100 \mathrm{pA} \underset{5 \mathrm{sec}}{\mathrm{L}}$

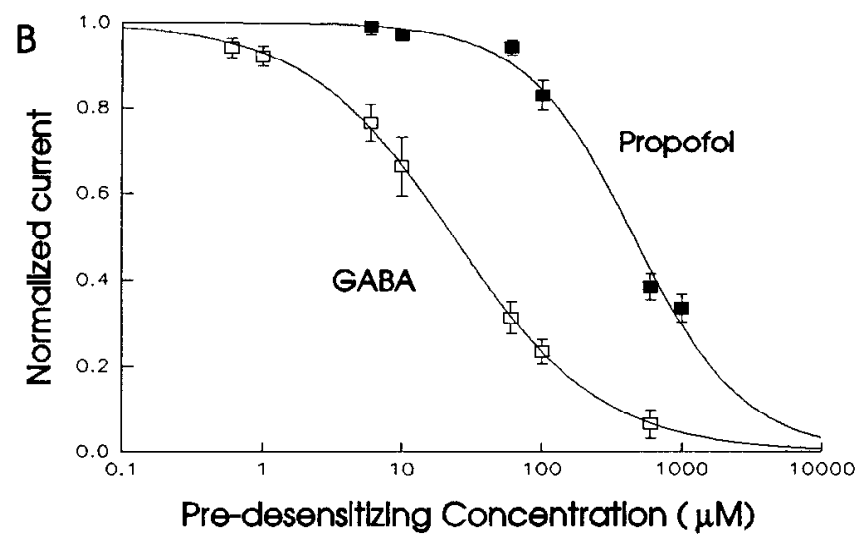

Figure 4. Predesensitization of the GABA receptors by GABA and propofol. The experimental protocol is illustrated in $A$. Following a 10 sec application of various concentrations of the predesensitizing agonists (GABA or propofol), a $2.5 \mathrm{sec}$ test pulse of GABA $(600 \mu \mathrm{M})$ was applied. The peak amplitude of the test responses was compared to control responses activated by GABA at $600 \mu \mathrm{M}$. $B$, The concentration-inhibition relationship of predesensitization for GABA and propofol. The ratios of the peak test and control responses were determined for various concentrations of GABA $(n=4)$ and propofol $(n=4)$ and values normalized the maximal control response. The concentration of agonist that reduced the test response by $50 \%$ and Hill coefficients for GABA and propofol were $23 \mu \mathrm{M}, n=0.81$ and $454 \mu \mathrm{M}, n=1$.1, respectively.

Figure 3. Propofol enhanced GABA-activated currents recorded at hyperpolarizing and depolarizing potentials. $A$, Currents were recorded with $\mathrm{CsCl}(140 \mathrm{~mm})$ in the pipette (mM: CsCl, $140 ; \mathrm{MgCl}_{2}, 2 ; \mathrm{CaCl}_{2}, 1$; TEA, 10; HEPES, 10; EGTA, 11) and standard cxtraccllular solution containing $140 \mathrm{~mm} \mathrm{NaCl}$. Leakage and capacitance currents measured in the absence of GABA or propofol were subtracted from the records. Membrane potential was changed in $20 \mathrm{mV}$ steps ranging from -80 to $+40 \mathrm{mV}$. GABA $(5 \mu \mathrm{M})$ currents were enhanced by propofol $(50 \mu \mathrm{M})$ at both hyperpolarizing and depolarizing membrane potentials. Note also that the kinetics of the GABA response is modified by propofol. In particular, at all voltages, the decay of the current upon removal of agonist is slowed to a similar extent as the current is potentiated. $B$, In another neuron, the after-response was observed during washout of high concentrations of propofol $(600 \mu \mathrm{M})$ when the cell was voltage clamped to $+20 \mathrm{mV}$.

the response to $\mathrm{GABA}(600 \mu \mathrm{M})$ was obtained and used to correct for any rundown of the currents.

The concentration that desensitized the amplitude of the test pulse by $50 \%$ was estimated from the plot of agonist concentration versus fractional desensitization (Fig. $4 B$ ). The half-maximal concentrations for GABA or propofol that induced desensitization were $23 \mu \mathrm{M}$ and $454 \mu \mathrm{M}$, respectively. Notably, the concentration of GABA that predesensitized the test response

by $50 \%$ was similar to the $\mathrm{EC}_{50}$ value $(19 \mu \mathrm{M})$ obtained for GABA-evoked currents (Fig. 1D). Previous investigators have also reported that the dose-response relationships for peak and steady-state GABA currents were similar (Frosh et al., 1992; Oh and Dichter, 1992).

In contrast, the half-desensitizing concentration of propofol was seven times larger than the apparent $\mathrm{EC}_{50}(61 \mu \mathrm{M})$ (Fig. 1C). Close examination of the dose-response relationships (Figs. $1 C, D ; 4 B$ ) indicated, however, that the relative potency of GABA and propofol was similar for both activation and desensitization. For example, $100 \mu \mathrm{M}$ propofol activated a current that was $66 \%$ of the maximal response to propofol and the maximal response to propofol was $31 \%$ of the maximal GABA response. Propofol $(100 \mu \mathrm{M})$ therefore activated $21 \%$ of the maximal GABA current, an effect equivalent to the response to $6 \mu \mathrm{M}$ GABA. These concentrations of propofol $(100 \mu \mathrm{M})$ and $\mathrm{G} \Lambda \mathrm{B} \Lambda(6 \mu \mathrm{M})$ also caused a similar degree of desensitization ( $17 \%$ and $23 \%$, respectively). Moreover, the lowest concentrations of propofol that caused detectable levels of desensitization of the GABA response were similar to the threshold concentrations of propofol required to directly activate the GABA receptors (Fig. $1 C$ ). This analysis assumes that propofol and $\mathrm{GABA}$ activate the $\mathrm{GABA}_{\mathrm{A}}$ receptor 
in a similar way and the dose-response curves describing occupancy of the receptor have similar shapes. For the reasons discussed below, the $\mathrm{EC}_{50}$ value for propofol activation of GA$\mathrm{BA}_{\mathrm{A}}$ channels was likely to be underestimated.

Propofol-evoked responses had a slow rate of onset compared to those activated by GABA. The time constant of the initial rate of onset for the current activated by propofol $(600 \mu \mathrm{M})$ was approximately $334 \pm 64 \mathrm{msec}$ and the average time to peak was $1.3 \pm 0.4 \mathrm{sec}$ ( $n=4$; holding potential, $-70 \mathrm{mV})$. In contrast, the onset of the response to GABA $(600 \mu \mathrm{M})$ was complete within the time taken to apply GABA to the neurons $(<30$ msec). The slow onset of propofol induced currents could have resulted from the time required for the drug to partition from the Intralipid vehicle to the receptors. However, increasing the concentration of Intralipid vehicle from two- to fivefold failed to alter the rate of onset or the amplitude of responses to 100 $\mu \mathrm{M}$ propofol (not shown). Slow onset kinetics were also observed when dimethyl sulfoxide was used as the vehicle (sce Fig. 5; Hara et al., 1993). Hence, the slow onset probably reflects slow rate of equilibration with the $\mathrm{GABA}_{\mathrm{A}}$ receptor. As a result, the peak response to propofol was likely underestimated because of desensitization occurring during the onset of the response. Receptor desensitization induced by propofol may account for some of the discrepancy between the $\mathrm{EC}_{50}$ of propofol for direct activation of inward currents and the half-maximal concentration of propofol that reduced the peak responses to GABA in the predesensitization paradigm (Fig. 1C).

Desensitization of GABA responses is strongly voltage dependent such that membrane depolarization decreases the rate and extent of desensitization (Fig. 3A; see also Hablitz, 1992). It was therefore predicted that the ratio of peak propofol to GABA currents should increase with depolarization, provided that the peak propofol current was actually underestimated due to desensitization whereas the GABA current was not. This prediction was borne out as the ratio was greater at depolarized compared to hyperpolarized holding potentials $(+20 \mathrm{mV}, 0.84$ $\pm 0.10, n=3 ;-70 \mathrm{mV}, 0.46 \pm 0.05, n=4$; Student's $t$ test, unpaired $p<0.01$; GABA and propofol, $600 \mu \mathrm{M})$. The outward rectification of the propofol current-voltage relationship observed by Hara et al. (1993) is also consistent with our suggestion that the maximal response to propofol may be reduced at hyperpolarizing potentials because of desensitization. It is notable that after-responses, which possibly reflect noncompetitive blockade of GABA receptors induced by high concentrations of propofol, were evident at both positive and negative membrane potentials (Figs. 1A, 3B).

Inward currents activated by saturating concentrations of GABA $(600 \mu \mathrm{M})$ rapidly reached a peak and then gradually declined towards a steady state as a consequence of desensitization. With high concentrations of GABA, the steady state was attained in $20 \mathrm{sec}$ and the time course of desensitization was well described by a biexponential function (Bormann and Clapham, 1985; Akaike et al., 1986; Ikemoto et al., 1988). We investigated the effects of propofol on the extent and rate of GABA receptor desensitization. Coapplication of GABA (600 $\mu \mathrm{M})$ and propofol $(10 \mu \mathrm{M})$ increased the time constants of desensitization $\left(\mathrm{GABA}\right.$ alone, $\tau_{f}=1.0 \perp 0.1 \mathrm{sec}, \tau_{s}=3.5 \perp 0.3$ $\mathrm{sec} ; \mathrm{GABA} \pm$ propofol, $\tau_{f}=1.5 \pm 0.3 \mathrm{sec}, \tau_{s}=4.7 \pm 0.5 \mathrm{sec}$; $n=5, p<0.01)$ but did not change the amplitude of the peak response (Fig. 5A).

The extent of desensitization of currents activated by saturating concentrations of GABA $(600 \mu \mathrm{M})$ was estimated from the ratio of the steady-state $\left(I_{\mathrm{ss}}\right)$ current to peak $\left(I_{p}\right)$ current $\left(I_{\mathrm{ss}}\right)$
$I_{p}$ ). A significant increase in this ratio was observed for responses to GABA $(600 \mu \mathrm{M})+$ propofol $(10 \mu \mathrm{M})$ compared to GABA alone: GABA, $I_{\mathrm{ss}} / I_{p}=0.09 \pm 0.02 ; \mathrm{GABA}+$ propofol, $I_{\mathrm{ss}} / I_{p}=$ $0.15+0.01(n=10, p<0.001)$. This enhancement is proportionately similar to the slowing of the rate of onset of desensitization. The ratio of steady-state current to peak current increased with propofol in a concentration-dependent manner and was evident at low concentrations that did not directly activate current (Fig. 5B).

The influence of propofol on desensitization of the GABA response was independent of the timing of the propofol application. Propofol increased the amplitude of the steady-state current whether it was coapplied with GABA at the onset of the response or applied after the GABA-evoked current had declined to a steady level (Fig. $5 C$ ). In contrast, coapplication of GABA and the Intralipid vehicle had no effect on the steadystate response or the rate of current decay. The propofol-induced change in steady-state level of desensitization of $\mathrm{GABA}_{\mathrm{A}}$ currents was also evident in previously published tracings (Hara et al., 1993; see Fig. 4B) where responses were induced by saturating concentrations of $\mathrm{GABA}$.

If we assume that most receptors are driven to the open state by the application of a saturating concentration of GABA (600 $\mu \mathbf{M})$ and that desensitization proceeds from the open state, then the amplitude of the steady-state current at equilibrium reflects both the forward rate constant of desensitization $\left(k_{f}\right)$ and the rate of recovery from the desensitized state $\left(k_{r}\right)$. Thus, the proportion of desensitized receptors is equal to $k_{f} /\left(k_{r}+k_{f}\right)$. Propofol's effect on the time course of recovery from desensitization must also be determined to describe fully the action of the drug on steady-state desensitization. The similarity between the change in the time constants of onset of desensitization and the amplitude of the steady-state current predicts that recovery from desensitization should not be affected by propofol.

The rate of recovery from desensitization was estimated using a double application protocol similar to that used by Sather et al. (1992). A conditioning application of a saturating concentration of GABA $(600 \mu \mathrm{M})$ or GABA $(600 \mu \mathrm{M})$ plus propofol $(10$ $\mu \mathrm{M})$ was applied and followed, at various time intervals by a test application of GABA or GABA and propofol, respectively. The time interval between the control and test applications was changed in incremental steps ranging from 1.25 to $120 \mathrm{sec}$ (Fig. $6 \mathrm{~A}$ ). The fraction of receptors in the desensitized state was determined at each time interval.

As expected (Fig. 5B), the steady-state level of the desensitization during the conditioning response to the combination of GABA and propofol was less than that produced by GABA alone. Fractional desensitization of the GABA and the combination responses at the end of the conditioning applications was $0.93 \pm 0.01$ and $0.87 \pm 0.01$, respectively $(n-7$, twotailed $p<0.0001)$. These data indicate that the steady-state response was approximately twice as great in the presence of 10 $\mu \mathrm{M}$ propofol. In the absence of propofol, recovery from desensitization proceeded in a biphasic manner that could be described as the sum of two exponential components with time constants $\tau_{f}=11 \mathrm{sec}$ and $\tau_{s}=69 \mathrm{sec}$, and intercepts $A_{f}=42 \%$ and $A_{s}-53 \%$. The time constants and intercepts in the presence of propofol were $\tau_{f}=8.4 \mathrm{sec}, \tau_{s}=60 \mathrm{sec}, A_{f}=41 \%$, and $A_{s}=$ $49 \%$. Thus, addition of $10 \mu \mathrm{M}$ propofol had minimal effect on the time constants for recovery from desensitization. These results also suggest that the steady-state current was enhanced by propofol because of a decrease in the slowly recovering component of desensitization induced by GABA. 

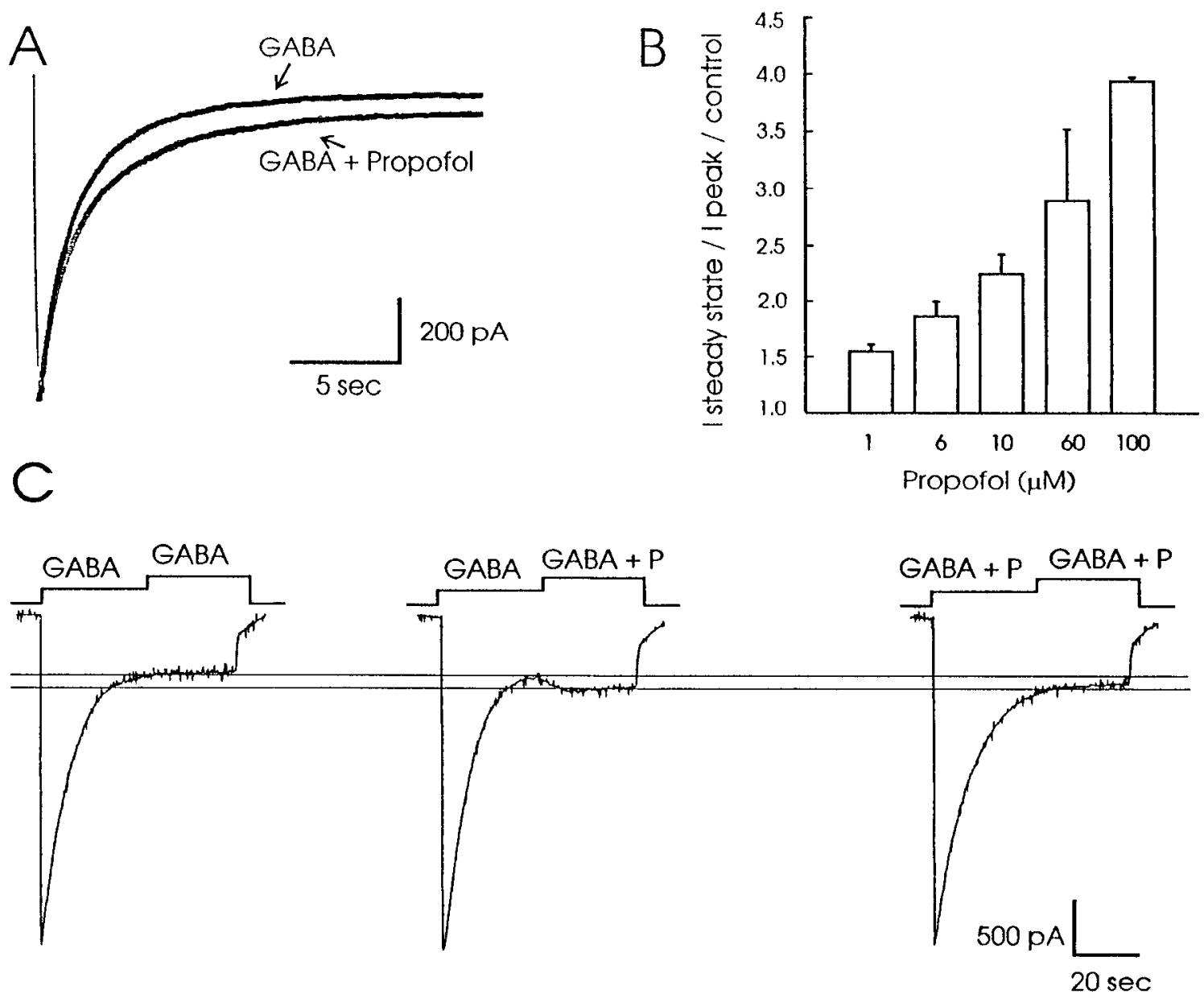

Figure 5. Propofol decreases the rate and extent of GABA receptor desensitization. $A$, Currents recorded from a single neuron in response to multiple applications of $600 \mu \mathrm{M}$ GABA $(n=4)$ or $600 \mu \mathrm{M}$ GABA plus $10 \mu \mathrm{M}$ propofol $(n=4)$ were averaged. The decay phase of the responses was fit with a biexponential equation and the fast $\left(\tau_{f}\right)$ and slow $\left(\tau_{s}\right)$ time constants determined. Propofol decreased the rate of current decay as indicated by an increase in the slow time constant. $B$, The ratio of steady-state current to peak current was determined for responses to $600 \mu \mathrm{M}$ GABA or GABA plus various concentrations of propofol. Multiple responses were recorded from a single neuron and values were normalized to the steady-state to peak current ratio measured in the absence of propofol. Data represent the mean \pm SEM for three to five applications at each concentration of propofol. $C$, Propofol reduced the extent of GABA receptor desensitization whether it was coapplied at the onset of the GABA response or applied after the current declined to a steady-state level. In this neuron, nystatin-perforated patch whole-cell recording technique was employed to minimize current rundown. An application of propofol $(10 \mu \mathrm{M})$ alone activated almost no current in this cell (not shown).

\section{Effects of propofol on single-channel properties of $G A B A$ receptors}

The properties of single-channel events activated by propofol $(2 \mu \mathrm{M})$, GABA $(2 \mu \mathrm{M})$, or GABA $(2 \mu \mathrm{M})$ plus propofol $(2 \mu \mathrm{M})$ were examined to determine if propofol increased the conductance, frequency, or duration of channel openings. Channel events were recorded from outside-out patches using symmetrical concentrations of choline $\mathrm{Cl}(140 \mathrm{mM})$. Patches were voltage clamped to $-60 \mathrm{mV}$ (internal or cytosolic membrane potential relative to the external membrane) and positioned in the outflow of one of the barrels of the perfusion system. In the absence of agonist, channel openings were infrequent or absent. When GABA was applied the channels typically demonstrated a high level of activity that then declined to a stable level. Once the activity had stabilized, records were obtained for single-channel analysis. Channels activated by GABA, propofol or the combination of GABA and propofol demonstrated mean current amplitudes of $1.55 \pm 0.04 \mathrm{pA}(n=7), 1.58 \mathrm{pA} \pm 0.07 \mathrm{pA}(n=6)$ and 1.58 $\pm 0.10 \mathrm{pA}(n=6)$, respectively (see Fig. $7 A)$. Close examination of the records revealed that channels activated by propofol and/ or GABA also occasionally exhibited at least one subconductance level with an amplitude of approximately $1.2 \mathrm{pA}$. The current-voltage relationship for propofol and GABA-gated events was linear between -90 and $-40 \mathrm{mV}$. All currents reversed at an extrapolated value of $0 \mathrm{mV}$ and the slope conductance for the main and subconductance state were $30 \mathrm{pS}$ and $21 \mathrm{pS}$, respectively. These values are similar to those previously reported for GABA-activated channel openings recorded from hippocampal, spinal, and cortical cells (Ozawa and Yuzaki, 1984; Bormann et al., 1987; Frosh et al., 1992). Neuroactive steroids, including pregnenolone and androsterone also directly activate GABA channcl cvents in spinal cord neurons with conductances of 28 and 20 pS (Twyman and Macdonald, 1992).

The kinetic properties of the main conductance state activated by propofol, GABA, or GABA and propofol were also examined. A detailed analysis of channel bursting or the effects of various concentration of propofol on channel gating was beyond the scope of this study. The frequency distribution of open time events activated by GABA, propofol, and coapplication of GABA and propofol were best described by the sum of two exponentials 


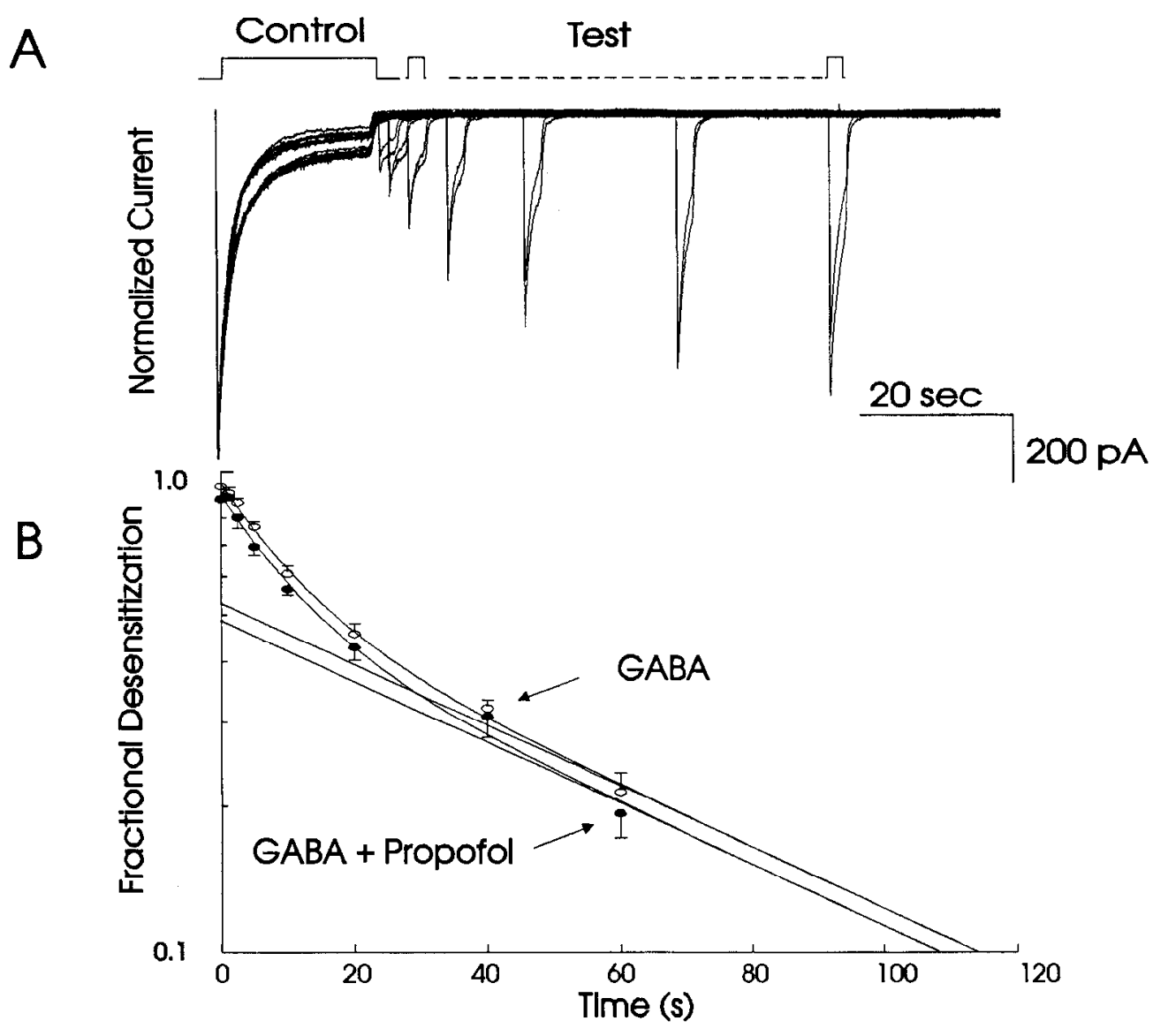

Figure 6. Time-dependent recovery from desensitization in the presence or absence of propofol. $A$ illustrates the experimental protocol. Conditioning responses were obtained by applying saturating concentrations of GABA (600 $\mu \mathrm{M})$ or GABA $(600 \mu \mathrm{M})$ and propofol (10 $\mu \mathrm{M})$ for 20 sec. Conditioning pulses were followed at various time intervals by a 2 sec application of GABA (600 $\mu \mathrm{M})$ or GABA (600 $\mu \mathrm{M})$ plus propofol (10 $\mu \mathrm{M})$. Peak conditioning responses were normalized to minimize the effect of current rundown during the protocol. Conditioning responses are superimposed on the left and test responses are shown to the right. The horizontal lines located above the current traces indicate the duration of agonist application. $B$, The effect of propofol on the time course of recovery from desensitization. The rate of recovery from the desensitized state was estimated from the relationship of fractional recovery to interpulse interval. The peak of the conditioning response was taken as zero (no receptors desensitized) whereas the baseline was considered to be equal to 1 (all receptors desensitized). At time zero (the end of the conditioning pulse), the fractional desensitization represented the average steady-state response. Data from six cells were averaged and fractional desensitization versus time plotted for the two groups. The recovery time constants were obtained by fitting a biexponential function to the data (Ikemoto et al., 1988). The time constants were, for GABA, $\tau_{f}=11 \mathrm{sec}, \tau_{s}=69 \mathrm{sec}$; GABA + propofol, $\tau_{f}=8.4, \tau_{s}=60 \mathrm{sec}$. The intercepts of the fast, slow, and steady-state components were, with GABA alone, $A_{f}=42 \%, A_{s}=53 \%, A_{\mathrm{ss}}=5 \%$; and in the presence of propofol, $A_{f}=41 \%, A_{s}=49 \%, A_{\mathrm{ss}}=9 \%$.

(Fig. 7B). The time constants for GABA-activated channel openings were $\tau_{f}=0.51 \pm 0.05 \mathrm{msec}$ and $\tau_{s}=2.8 \pm 0.7 \mathrm{msec}$ $(n=6)$. The fast and slow time constants from fits of histograms for propofol-activated openings were $\tau_{f}=0.40 \pm 0.07 \mathrm{msec}$ and $\tau_{s}=2.9 \pm 0.7 \mathrm{msec}(n=3)$. These values are similar to time constants previously reported for GABA-evoked events recorded from chick cerebral neurons $\left(\tau_{f}-0.39 \mathrm{msec}\right.$ and $\tau_{s}=2.1$ msec; Weiss et al., 1988). Neither the slow nor fast components of GABA-activated events were substantially influenced by addition of propofol to the perfusate $\left(\tau_{f}=0.58 \pm 0.05 \mathrm{msec}, \tau_{s}=\right.$ $3.0 \pm 0.3 \mathrm{msec} ; n=6$ ) (Fig. $7 B$ ). Propofol-activated events had an average open duration of $2.3 \pm 0.4 \mathrm{msec}$. Similarly, the average open duration of events recorded during applications of GABA or GABA and propofol were $2.3 \pm 0.7 \mathrm{msec}$ and 2.6 $\pm 0.3 \mathrm{msec}$, respectively. These values are similar to mean open duration previously reported for GABA channels (Mienville and Vicini, 1989; Twyman and Macdonald, 1992).

We also investigated the frequency of opening events and the open state probability of channel opening. A large variation in the frequency of channel openings was observed between dif- ferent patches, presumably because of differences in the number of channels present in each patch. Therefore, to compare the frequency of channel opening and the open state probability under the various recording conditions, values were normalized to those obtained when patches were perfused with GABA alone. In all patches examined, the addition of propofol $(2 \mu \mathrm{M})$ to GABA $(2 \mu \mathrm{M})$ incrcased the frequency of opening compared to the frequency observed with GABA alone $(n=6)$; the ratio of frequency of opening of GABA plus propofol to GABA alone was $2.2 \pm 0.3(n=6, p<0.05)$, whereas the ratio of propofol alone to GABA alone was $0.5 \pm 0.2(n=3)$. Similarly, the open state probability with propofol plus GABA was $3.1 \pm 1.1$-fold $(n=6, p<0.05)$ greater than with GABA alone whereas the open state probability was less with propofol alone than with GABA alone $(0.55 \pm 0.24, n=3)$. In summary, these results indicate that propofol $(2 \mu \mathrm{M})$ increased the frequency and probability of channel opening rather than prolong channel open time. It is therefore likely that the potentiation of GABA-mediated whole-cell currents by propofol results from an increase in the frequency of channel opening. 
A
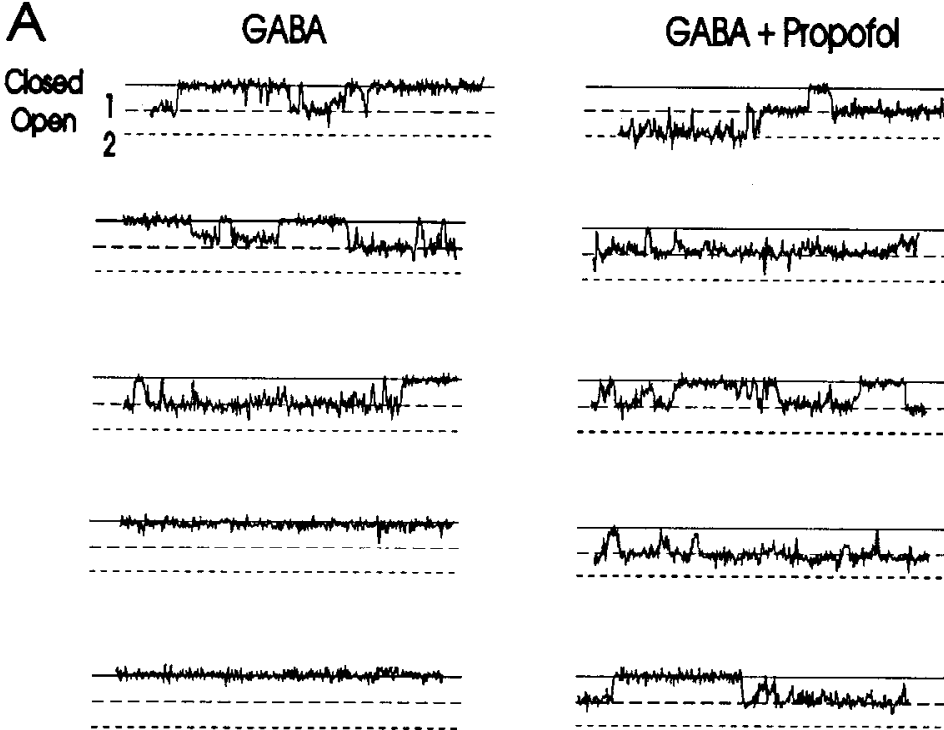

B

\section{Open TIme Histograms}

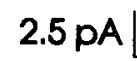

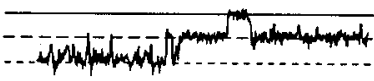
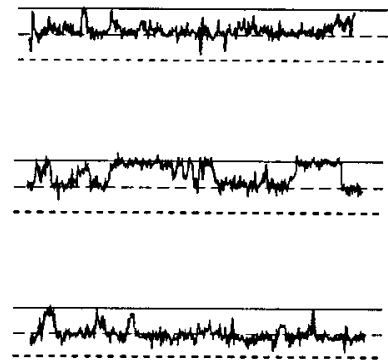

$2.5 \mathrm{pA}$

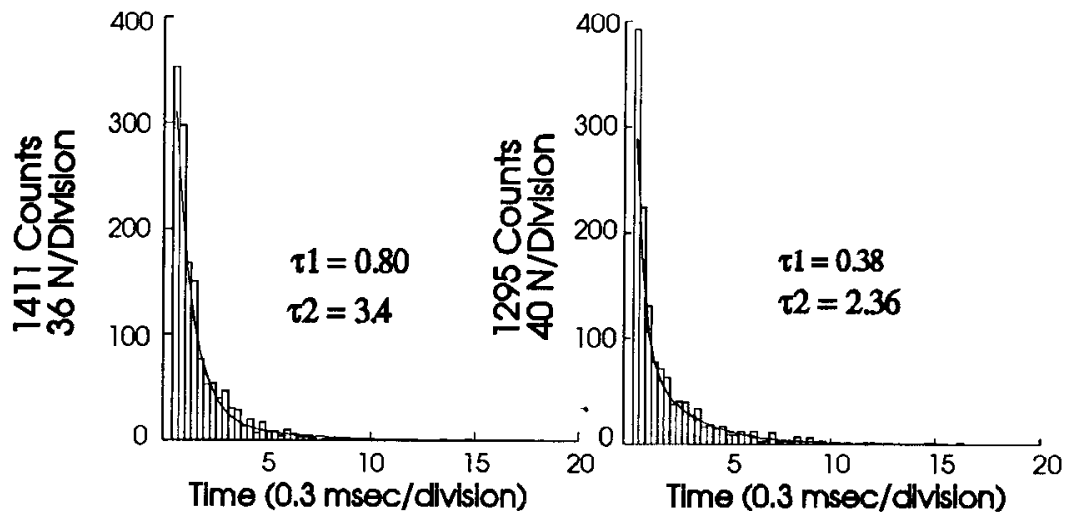

Figure 7. $A$, Single-channel currents recorded from outside-out patches obtained from the hippocampal neurons are illustrated. The pipette solution and extracellular solution contained choline $\mathrm{Cl}$ (140 mm) and the palch was vollage clamped to $-60 \mathrm{mV}$. Traces represent currents digitized at $0.1 \mathrm{msec}^{\text {point }}{ }^{-1}$ and low-pass filtered at $2 \mathrm{kHz}(-3 \mathrm{~dB})$. Inward current is represented by a downward deflection in all traces. The addition of $2 \mu \mathrm{M}$ propofol to the perfusate containing $2 \mu \mathrm{M}$ GABA caused an increase the frequency of channel opening. $B$, The open time histograms for the records illustrated in $A$ are indicated below the tracings. The histograms were fit with a biexponential function, and the fast $\left(\tau_{f}\right)$ and slow $\left(\tau_{s}\right)$ time constants are indicated. The frequency histograms were composed of similar number of events and indicate that propofol had no apparent affect on the time constants of channel opening.

\section{Effects of propofol on mIPSCs}

Miniature inhibitory postsynaptic currents (mIPSCs) were recorded following the application of hypertonic sucrose to the cell soma. The decay phase of mIPSCs was best described by a biexponential function. The fast and slow time constants were approximately 6 and $30 \mathrm{msec}$, respectively, with the fast component dominating the decay phase. These values are similar to those previously reported (Weiss et al., 1988; Pearce, 1993). The addition of propofol $(0.5-2 \mu \mathrm{M})$ to the bath caused a concentration-dependent increase in both the fast and slow time constants of current decay but had little effect on the average amplitude. When the decay phase was fitted to a single exponential component, the decay phase increased from $19 \mathrm{msec}$ in the absence of propofol to $45 \mathrm{msec}$ in the presence of propofol $(2 \mu \mathrm{M})$, an increase similar to the increase in the opening ratio of single channels produced by the same concentration of propofol (2.3-fold vs 2.5-3-fold). Examples of averaged mIPSCs are illustrated in Figure 8. Prolongation of mIPSCs was observed in all neurons tested $(n=3)$. The observation that the decay time constant of the mIPSCs is much greater than the mean open time of the GABA channels implies that even in the absence of propofol, the channels reopen during the falling phase of the mIPSCs. Hence, an increase in the opening rate by propofol would be expected to lead to a prolongation of the mIPSCs as is observed here.

\section{Kinetic model of receptor gating by GABA and propofol}

In order to summarize the data, we have developed a minimal kinetic scheme for gating and desensitization of GABA receptors. This was used to simulate the actions of GABA, propofol, and combinations of these agonists. The model is presented as a plausible illustrative explanation rather than an optimized solution. The first step is to define the gating by GABA alone. The core of our model is based on one originally proposed by Weiss and Magelby (1989) to describe the kinetics of single $\mathrm{GABA}_{\mathrm{A}}$ channels. In our model activation is regulated by the sequential binding of two agonist molecules followed by an isomerization step to the open state. For simplicity, two additional open states of the $\mathrm{GABA}_{\mathrm{A}}$ receptor, required to describe single-channel kinetics (Weiss and Magelby, 1989), were ignored as they are of low probability in the presence of high agonist concentrations. Otherwise, the rates used to describe channel activation by GABA are identical to those reported previously. These rate constants for GABA are $k_{1}=4 \times 10^{7} / \mathrm{M} / \mathrm{sec}, k_{2}=$ 


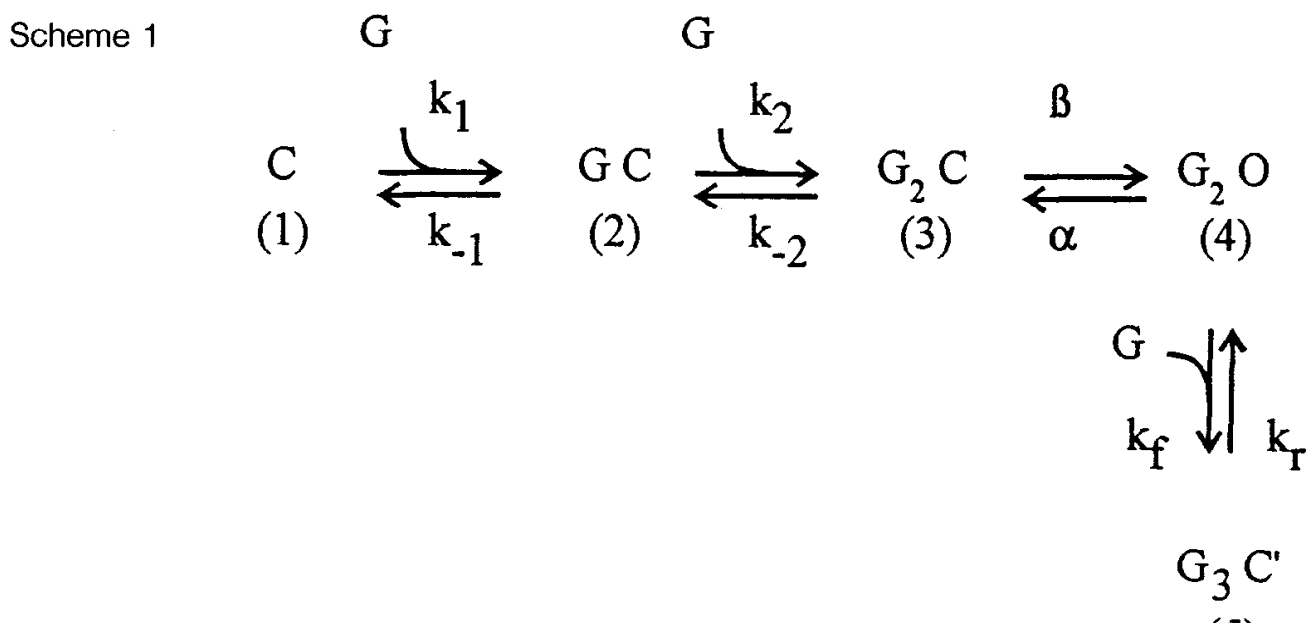

\section{note $\mathrm{C}=$ closed state, $\mathrm{O}=$ open state, $\mathrm{G}=$ agonist concentration, $\mathrm{C}^{\prime}=$ desensitized closed state}

$1.3 \times 10^{7} / \mathrm{M} / \mathrm{sec}, k_{-1}=130 / \mathrm{sec}, k_{-2}=610 / \mathrm{sec}, \beta=1100 / \mathrm{sec}$, $\alpha=490 /$ sec (Weiss and Magelby, 1989). The rate of desensitization increases with agonist concentration in parallel with the peak response. Moreover, the $\mathrm{EC}_{50}$ for pre-desensitization and for the peak response were similar. This behavior is not readily reproduced by traditional cyclic models of desensitization which predict a higher agonist affinity for the desensitized receptor than for the non-desensitized receptor (see Katz and Thesleff, 1957; Pennefather and Quastel, 1982). The results can be simulated by a sequential model where desensitization develops from the open state (4) in a manner that requires the binding of at least one additional agonist molecule. The rate of onset of desensitization saturates, suggesting that binding to the desensitization site is no longer the rate limiting step at higher agonist concentrations and additional steps are involved. For simplicity however, we have described these steps by a single rate constant $\left(k_{f}\right)$ equal to $(2 / \mathrm{sec}) /(1+0.15 \mathrm{~mm} /[\mathrm{GABA}])$. Although there appear to be two components of desensitization, we have only considered a single component. Recovery was governed by a single rate constant $\left(k_{r}\right)$ equal to $0.1 / \mathrm{sec}$. These rates combined with the maximum open probability $(0.69$, determined by the isomerization rates $\alpha$ and $\beta$ ) predict a maximal steady state level of desensitization of $93 \%$. Scheme 1 summarizes the kinetic model.

Because concentrations of propofol that did not directly activate the receptor enhanced GABA-evoked currents, we have assumed that propofol increased the potency of GABA. This action would have to be mediated by propofol binding to an allosteric site distinct from the GABA binding site and was simulated by proposing a series of five parallel states (Scheme $1 P$ ), analogous to the five states seen in the presence of GABA alone (Scheme 1). For simplicity, we also have assumed that propofol binds equally well to the allosteric sites on all five states of Scheme 1 with rate constants $k_{+p}=3 \times 10^{5 / \mathrm{M}} / \mathrm{sec}$ and $k_{-p}$ $=3 / \mathrm{sec}$ (see Scheme 2). These rates were chosen to ensure that $K p=k-p / k p=10 \mu \mathrm{M}$ (see Fig. $5 B$ ). To account the increase in potency of GABA (Fig. $2 D$ ), we allowed occupancy of the allosteric site by propofol to produce a decrease in the rates of dissociation of GABA or propofol from the agonist binding site by 20 -fold so that $k_{-1 p}=0.65 / \mathrm{sec}$ and $k_{-2 p}=3 / \mathrm{sec}$. The maximal microscopic rate of desensitization of the propofol associated receptor was reduced fourfold $\left(k_{f p}=0.5 / \mathrm{sec}\right)$ to account for the observed decreased rate of onset and extent of desensitization while the rate of recovery was unchanged $\left(k_{r p}=k_{r}\right)$. All other rate constants were left the same as those used in Scheme 1. Thus, Scheme 2 predicts that with $10 \mu \mathrm{M}$ propofol, $50 \%$ of the allosteric sites would be occupied by propofol, and receptors would desensitize at one-fourth of the normal rate so that the overall rate of desensitization would be slowed 1.6-fold. For high concentrations of propofol (see Fig. 6), the maximum possible level of desensitization predicted by the model would decrease from $93 \%$ to $77 \%$. In other words, the steady-state response could increase by as much as 3.3-fold (see Fig. $5 B$ ).

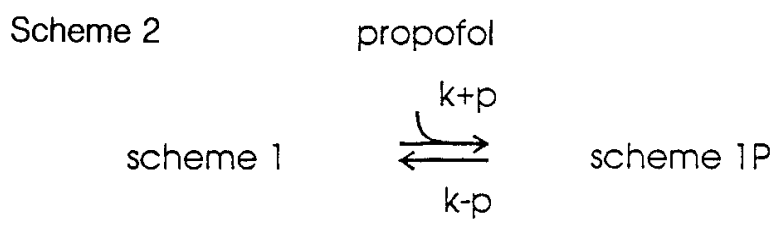

Propofol also directly activates $\mathrm{GABA}_{\mathrm{A}}$ receptors, possibly by binding in the vicinity of the GABA recognition site as the response is inhibited by bicuculline (Hara et al., 1993). The affinity of propofol was less than that of GABA, as are the rates of onset and offset of the response. These actions were simulated by reducing the rates of binding and dissociation of propofol relative to those of GABA. The forward rates $\left(k_{1}\right.$ and $\left.k_{2}\right)$ were decreased 4000-fold and the dissociation rates $\left(k_{-1}\right.$ and $\left.k_{-2}\right)$ were decreased 10-fold. All other rate constants were the same. These changes allowed the model to reproduce the slow rate of activation of propofol-induced currents while maintaining the observed potency of propofol relative to GABA. The slow rates may reflect a requirement that propofol must first accumulates in the cell membrane before binding to its receptor site. 
Control

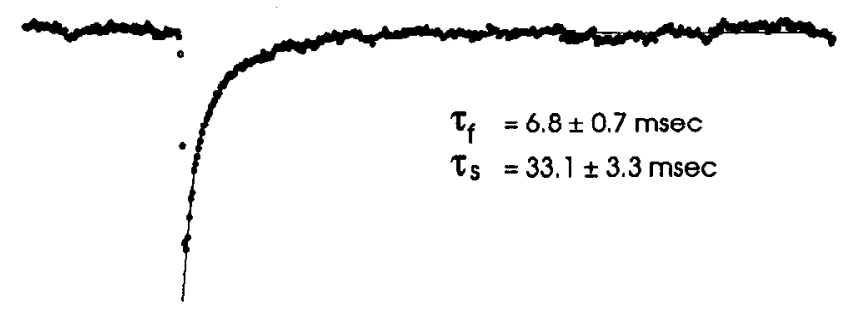

Propofol $0.5 \mu \mathrm{M}$

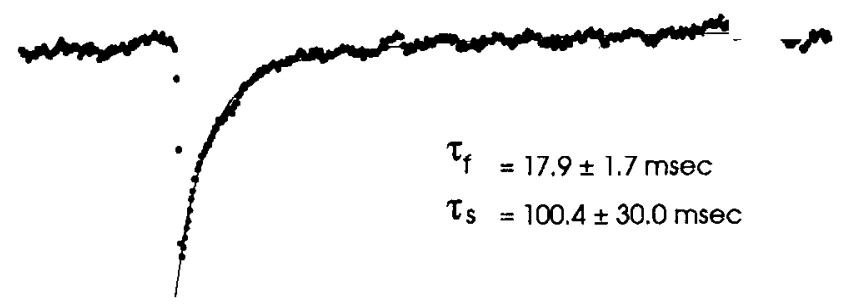

Propofol $2 \mu \mathrm{M}$

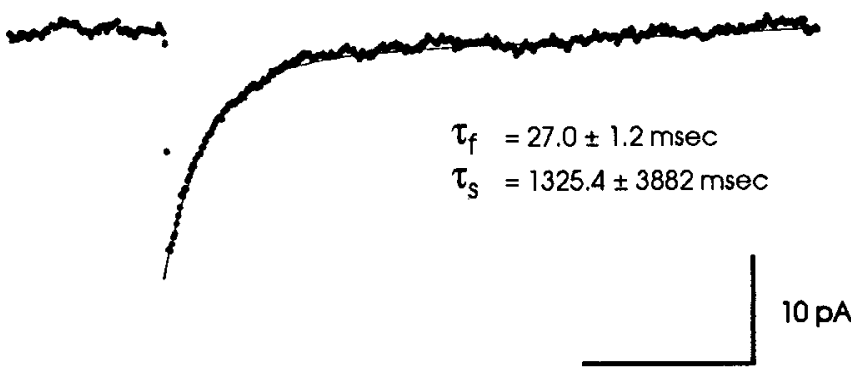

$51.2 \mathrm{msec}$

Figure 8. The effects of propofol on inhibitory synaptic transmission. $1, \Lambda$ typical example of the averaged mIPSCs induced by applications of hypertonic sucrose, prior to and following the addition of $0.5 \mu \mathrm{M}$ and $2 \mu \mathrm{M}$ propofol to the bath solution. Traces represent the average of 54 $61 \mathrm{mIPSCs}$ fitted to a biexponential decay function. The fast $\left(\tau_{f}\right)$ and slow $\left(\tau_{s}\right)$ time constants are indicated. The intercepts for the fast $\left(A_{f}\right)$ and slow $\left(A_{s}\right)$ components were, for control, $A_{f}=-12.5 \pm 0.72, A_{s}=$ $-6.3 \pm 0.8$; for $0.5 \mu \mathrm{M}$ propofol, $A_{f}=-11.97 \pm 0.7, A_{s}-3.0 \pm 0.8$; and for $2 \mu \mathrm{M}$ propofol, $A_{f}=-12.2 \pm 0.3, A_{s}-7.4 \pm 17.5$. The concentration-dependent decrease in the rate of decay of currents was also evident when currents were fit with a single exponential. These time constants were $19.4 \mathrm{msec}, 29.6 \mathrm{msec}$, and $44.5 \mathrm{msec}$ for control, 0.5 $\mu \mathrm{M}$ propofol, and $2 \mu \mathrm{M}$ propofol, respectively. Propofol at $2 \mu \mathrm{M}$ decreased the rate of decay 2.5-fold, similar in degree to the increase in the frequency of channel opening assessed from single-channel measures (see above). Currents were abolished by bath applications of bicuculline ( 2 $\mu \mathrm{M})$.

Using this model, we were able to reproduce the results illustrated in Figure 4. Figure $9 A$ shows that a $20 \mathrm{sec}$ application of a low concentration of GABA $(2 \mu \mathrm{M})$ caused a small rapidly developing response. Co-application with $50 \mu \mathrm{M}$ propofol increased the response almost 10 fold while application of propofol alone produced only a small, slowly developing response. Figure $9 B$ shows that a $20 \mathrm{sec}$ application of a saturating concentration of GABA $(600 \mu \mathrm{M})$ caused a rapidly rising response that increased and then decayed to a steady-state level that was approximately $7 \%$ of the peak response. Coapplication of GABA
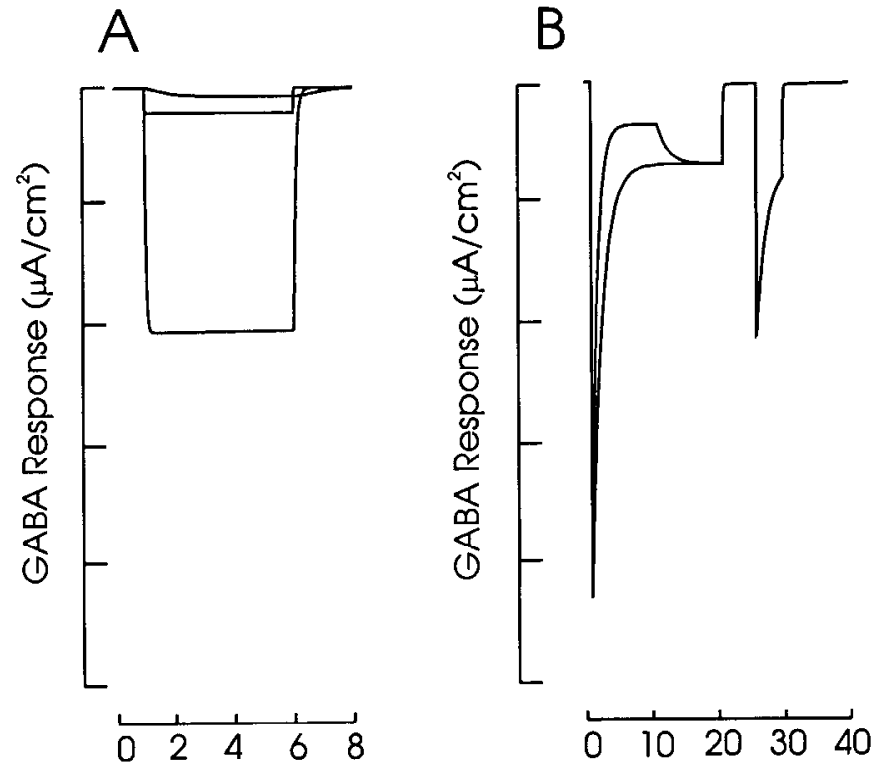

\section{Time (sec)}

Figure 9. Simulation of the allosteric modulation of GABA receptors by propofol. $A$, potentiation of response to $2 \mu \mathrm{M}$ GABA by $50 \mu \mathrm{M}$ propofol. The three traces represent the simulated current response to $50 \mu \mathrm{M}$ propofol alone (smallest), $2 \mu \mathrm{M}$ GABA alone and $50 \mu \mathrm{M}$ propofol $+2 \mu \mathrm{M}$ GABA (largest response). $B$, Reduction of GABA desensitization by $20 \mu \mathrm{M}$ propofol. The simulated protocol is similar to that described in Figure $5 C$. Propofol is added $10 \mathrm{sec}$ after exposure to $600 \mu \mathrm{M}$ GABA when the GABA response has reached a steady-state level of desensitization. Propofol doubles the steady-state response. When $20 \mu \mathrm{M}$ propofol is present throughout the application of $600 \mu \mathrm{M}$ GABA, the response desensitizes more slowly but the same steady-state response is attained. A second brief pulse of GABA applied after the long pulse indicates the slow recovery from desensitization.

and $20 \mu \mathrm{M}$ propofol slowed the rate of onset of desensitization and increased the steady-state response. If the same concentration of propofol was added after the steady-state was achieved, an increase in the steady-state response was observed, similar to that observed experimentally (see Fig. $5 D$ ).

During washout of high concentrations of propofol, an increase in current was observed. Similar after-responses have been reported for nicotinic receptors following activation by high concentrations of $\mathrm{ACh}$ and have been attributed to blockade of the channel by the agonist (Colquhoun and Sakmann, 1985). Incorporating a noncompetitive blocking action by propofol reproduced the after-response as illustrated in Figure $9 B$. Our data are consistent with an $\mathrm{IC}_{50}$ for this effect of approximately $1 \mathrm{~mm}$. For simplicity, we assumed the blockade does not discriminate among the 10 states of Scheme 2 and is governed by a forward rate constant $k_{+B}=10^{6} / \mathrm{M} / \mathrm{sec}$ and an unblocking rate constant $k_{-B}=1000 / \mathrm{sec}$. Hence, the block can be described by Scheme 3.

$\begin{array}{ll}\text { Scheme } 3 & \text { propofol } \\ \text { scheme 2 } & \underset{k-B}{k}\end{array}$ scheme 2B




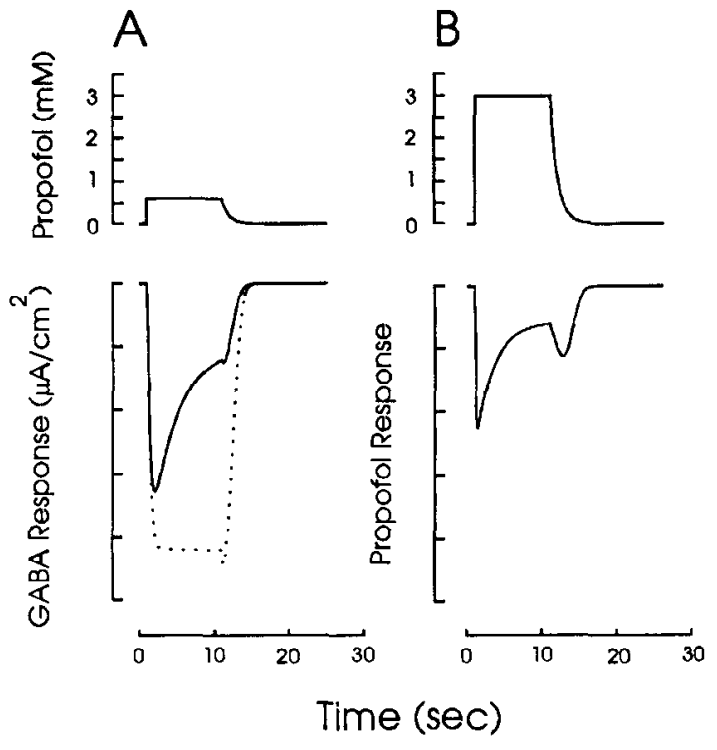

Figure 10. Simulation of the direct receptor activation effects of propofol. The top panels indicate the concentration of propofol present in the extracellular space. Note that the concentration is assumed to rise instantaneously and decline with a time constant of $1 \mathrm{sec}$. The bottom panels illustrate the current predicted from a cell with a maximal propofol conductance of $1 \mathrm{mS} \mathrm{cm}^{-2}$. $A$, Response to $0.6 \mathrm{~mm}$ propofol. The dotted line is the response expected if no desensitization occurred. This was simulated by setting $k_{f}$ and $k_{f p}=0$. Note that desensitization leads to attenuation of the peak response. $B$, Response to $3 \mathrm{~mm}$ propofol. Note that the peak is smaller despite the higher concentration of agonist and a large atter-response is observed.

The slow recovery from blockade implied by the slow rise time of the after-responses observed in our experiments suggests that either propofol dissociates slowly from the sites governing the block or that propofol washes away slowly. A slow rate of dissociation, combined with a low affinity, would imply an unusually slow rate of association with the blocking site. Since the blockade developed quickly, we are force to assumed that the slow time course reflects slow removal of propofol from the vicinity of the blocking site. This slow rate would be expected if propofol accumulated locally in a hydrophobic storage pool such as the membrane of the cell. Figure $10, A$ and $B$, shows the results predicted by the model for the response to 0.6 and $3 \mathrm{~mm}$ propofol where propofol washes away with a time constant of $1 \mathrm{sec}$. Because of the noncompetitive channel blockade, the after-response is more prominent and prolonged and the peak response is less with $3 \mathrm{~mm}$ propofol compared to response to $0.6 \mathrm{~mm}$. The larger response in Figure $10 \mathrm{~A}$ indicates the response to $0.6 \mathrm{~mm}$ propofol expected if there where no desensitization. It is clear that because of the slow rate of onset of the response, the peak current underestimates the potential fractional activation of the GABA receptor by propofol that would occur if there was no desensitization.

\section{Discussion}

The experiments reported here and previous work (Hale and Lambert, 1992; Hara et al., 1993) indicate that propofol has multiple effects on the $\mathrm{GABA}_{\mathrm{A}}$ receptor. We have interpreted our results as indicating that propofol has three distinct actions depending on the concentration examined: low concentrations of propofol $(2-100 \mu \mathrm{M})$ potentiate GABA-activated currents, increase the frequency of channel opening, and reduce the rate of receptor desensitization possibly through an allosteric interaction with the $\mathrm{GABA}_{\mathrm{A}}$ receptor; intermediate concentrations (10-2000 $\mu \mathrm{M})$ directly activate and desensitize the receptor, whereas extremely high concentrations produce a noncompetitive receptor inhibition.

The $\mathrm{EC}_{50}$ value for GABA activation of GABA currents compares favorably with values previously reported for cultured cortical neurons (20 $\mu \mathrm{M}$; Frosh et al., 1992) and GABA channels expressed in Xenopus oocytes (20 $\mu \mathrm{M}$; Sigel and Baur, 1988). The $\mathrm{EC}_{50}$ value for direct activation of $\mathrm{GABA}_{\mathrm{A}}$ channel by propofol $(61 \mu \mathrm{M})$ was higher than that recently reported by Hara et al. (1993) for currents recorded from acutely isolated hippocampal pyramidal neurons $(12 \mu \mathrm{M})$. This difference may reflect the vehicle (dimethyl sulfoxide) used in that study. The free concentration of a highly lipid-soluble drug such as propofol, dispersed in an aqueous medium, will be greater if the drug is first dissolved in a polar solvent (ethanol or DMSO) rather than vehicles used clinically such as Intralipid or cremophor EL that form micelles (Pennefather et al., 1980).

Independent of the vehicle used, however, the $\mathrm{EC}_{50}$ for propofol underestimates the true affinity of propofol for the site governing direct activation since the slow onset of propofol action allows significant desensitization before the peak is attained. Similarly, desensitization may lead to an underestimation of the Hill coefficients which define the relation between peak response and agonists concentration as desensitization affects the peak response to high concentrations of agonist more than response to lower agonist concentrations (see Pennefather and Quastel, 1982). The Hill coefficients observed experimentally were 1.3 and 1.2 for GABA and propofol responses, respectively, while the Hill coefficients predicted by our model were 1.5 and 2.0 , respectively.

Our experimental and simulated data suggest that high concentrations of propofol block the receptor noncompetitively. In order to account, in our model for the slow time course of the after-response during drug washout, we postulated that propofol takes time $(\tau=1 \mathrm{sec})$ to be washed away from the vicinity of the receptor possibly due to accumulation in the cell membrane.

Several $\mathrm{GABA}_{\mathrm{A}}$ receptor agonists including pentobarbitone, alphaxalone, and etomidate also depress the response and produce an after-response during drug washout (Akaike et al., 1986; Robertson, 1987; Ikemoto et al., 1988). Recently we have observed that high concentrations of propofol also inhibit NMDA but not kainate responses in a noncompetitive manner (Orser et al., 1993).

The effects of propofol on the GABA dose-response curve were found to be similar to those produced by pentobarbitone and several benzodiazepines (Silvilotti and Nistri, 1991; Sieghart, 1992). Propofol shifted the curve to the left without changing the maximal current response. Our single-channel studies indicated that propofol enhancement of GABA-activated currents results primarily from an increase in the frequency of channel opening rather than a prolongation of channel open time or increase in single-channel conductance. Similar to our findings, benzodiazepines have been reported to enhance GABA currents by increasing the probability and frequency of channel opening without increasing the mean channel open time (Vicini et al., 1987).

Our studies of mIPSCs also demonstrated that low concentrations of propofol $(0.5-2 \mu \mathrm{M})$ influenced inhibitory synaptic events. As with pentobarbitone, halothane, diazepam, and ketamine (Gage and Robertson, 1985; Otis and Mody, 1992), 
propofol decreased the rate of decay of the MIPSC without effecting its amplitude. An increase in the frequency of channel opening may account for prolongation of synaptic events. It is of interest that $2 \mu \mathrm{M}$ propofol reduced the rate of decay of mIPSCs 2.3-fold, similar to the 2.2-fold change in the frequency of single-channel events observed when $2 \mu \mathrm{M}$ propofol was added to $2 \mu \mathrm{M}$ GABA. It is likely that the decay rate of mIPSCs reflects the repetitive opening of GABA channels since the decay time was $19 \mathrm{msec}$ and $45 \mathrm{msec}$ in the absence and presence of propofol and the mean channel open time was $2.3 \mathrm{msec}$ and $2.6 \mathrm{msec}$ under those conditions.

The half-maximal concentrations of GABA required for activation and for producing the desensitized state were similar. In contrast to our findings, the half-maximal concentrations of $\mathrm{ACh}$ and glutamate that desensitize the nicotinic and NMDA receptor, respectively, are much lower than those that activated receptors (Sather et al., 1992; Franke et al., 1993). The higher affinity of the desensitized state of these receptors for agonist is expected from the cyclic equilibrium models of desensitization (Katz and Thesleff, 1957; Pennefather and Quastel, 1982). With such models, exposure to low concentrations of agonist leads to trapping of receptors in the agonist-bound desensitized form and receptors can recover from desensitization at a much slower rate than the agonist-bound open state enters the desensitized state. The reverse is true for agonist free receptors and the cycle is balanced by the difference in agonist affinity between the desensitized and nondesensitized receptors. In our simulation, we accommodate the similar affinity for the desensitized and nondesensitized receptors by proposing a sequential model of desensitization governed by the occupancy of a third binding site for agonist, distinct from the two binding sites involved in activation of the channel.

Direct channel activation and desensitization induced by propofol may result from propofol binding in the vicinity GABA recognition site. Propofol was approximately 20 -fold less effective than GABA at producing an equivalent level of activation and desensitization. Hence, as with GABA the potency of propofol for activation and desensitization were similar and propofol must interact with the GABA binding sites governing both activation and desensitization in a manner similar to GABA. Binding studies support an interaction of propofol with the GABA recognition site. Bicuculline inhibited the reduction of ${ }^{35} \mathrm{~S}-\mathrm{TBPS}$ binding by propofol and propofol-enhanced ${ }^{3} \mathrm{H}-\mathrm{GABA}$ binding (Concas et al., 1991) as well as propofol-induced $\mathrm{Cl}^{-}$flux (Hara et al., 1993).

The effects of low concentrations of propofol, on the other hand, may result from allosteric modulation of the receptor/ channel complex. Propofol enhanced responses to GABA to a greater extent than was predicted from the direct effects of propofol alone. Whole-cell recordings indicated that propofol enhanced the response to GABA more than what was predicted from the summed effects of propofol and GABA alone. Low concentrations of propofol may allosterically enhance $\mathrm{GABA}_{\mathrm{A}}$ receptor function, in a manner similar to several other anesthetics drugs (Sieghart, 1992).

Allosteric modulation of the receptor/channel complex, by low concentrations of propofol, may also account for the observed reduced rate of desensitization. In apparent contrast to our findings, benzodiazepines have been reported to enhance receptor desensitization (Mierlak and Farb, 1988; Frosch et al., 1992). This discrepancy possibly results from the differences in experimental design. We examined the effects of propofol on responses to concentrations of GABA that produced a maximal peak response. Previous investigators used subsaturating concentrations of agonist so that in those experiments benzodiazepines and barbiturates enhanced the peak response to GABA. Similar to our findings (Figs. $1 A, B ; 10 A$ ), the rate of desensitization has previously been shown to increase with increasing concentrations of agonist, in parallel with the increase in the amplitude of the peak response. When the rate of desensitization is corrected for the enhanced peak response, diazepam $(20 \mu \mathrm{M})$ no longer increases the rate of desensitization (see Frosch et al., 1992, their Figs. 5C, 6C).

Facilitation of GABA-mediated inhibitory transmission by propofol likely contributes to the drug's neurodepressive properties. The blood concentrations of propofol that induces hypnosis in humans range from 1.5 to $6 \mu \mathrm{g} / \mathrm{ml}(8-34 \mu \mathrm{M})$. Most patients awaken when concentrations decrease below $1 \mu \mathrm{g} / \mathrm{ml}$ (Shafer et al., 1988). The concentration of propofol at inhibitory synapses in the CNS is not known, as propofol is highly lipophilic and binds tightly to serum proteins.

Propofol also causes excitatory phenomena such as epileptiform movements, seizures, or opisthotonos (for review, see Sneyd, 1992). These excitatory events are uncommon but tend to occur following rapid injection of a large bolus of the drug, following the termination of a prolonged infusion, or in patients receiving other medications that influence the seizure threshold. It was suggested that neuroexcitation associated with propofol may be a consequence of disinhibition of GABA receptors that occurs following their desensitization by propofol (Hara et al., 1993; Ries et al., 1994). Our results indicate that significant desensitization develops only at moderately high concentrations of propofol. Indeed, clinically effective concentrations of propofol decreases the rate of decay of mIPSCs and should potentiate inhibitory influences. There are, however, several indirect ways that enhanced GABA-mediated responses can alter neuronal synchronization and enhance excitation (for discussion, see Orser, 1994).

Like most anesthetics, propofol influences other non-ligandand ligand-regulated ion channels, including sodium, potassium, $\mathrm{Ca}^{2+}$, NMDA, and $\mathrm{ACh}$ receptor/channels (Frenkel and Urban, 1991; Magnelli et al., 1992; Wachtel and Wegrzynowics, 1992; Orser et al., 1993), and modulation of these channels might contribute to propofol's clinical effects. However, of these receptor targets, the GABA receptor appears to be most sensitive to propofol's actions, suggesting that enhancement of inhibitory synaptic transmission plays a key role in propofol's anesthetic properties.

\section{References}

Akaike N, Inoue M, Krishtal OA (1986) 'Concentration-clamp' study of $\gamma$-aminobutyric-acid-induced chloride current kinetics in frog sensory neurones. J Physiol (Lond) 379:171-185.

Barker JL, Harrison NL, Lange DG, Owen DG (1987) Potentiation of $\gamma$-aminobutyric-acid-activated chloride conductance by a steroid anaesthetic in cultured rat spinal neurones. J Physiol (Lond) 386:485501.

Bekkers JM, Stevens CF (1989) NMDA and non-NMDA receptors are colocalized at individual excitatory synapses in cultured rat hippocampus. Nature 341:230-233.

Bormann J, Clapham DE (1985) $\gamma$-Aminobutyric acid receptor channels in adrenal chromaffin cells: a patch-clamp study. Neurobiology $82: 2168-2172$.

Bormann J, Hamill OP, Sakmann B (1987) Mechanism of anion permeation through channels gated by glycine and $\gamma$-aminobutyric acid in mouse cultured spinal neurones. J Physiol (Lond) 385:243-286. 
Collins GGS (1988) Effects of the anaesthetic 2,6-diisopropylphenol on synaptic transmission in the rat olfactory cortex slice. Br J Pharmacol 95:939-949.

Colquhoun D, Sackmann B (1985) Fast events in single-channel currents activated by acetylcholine and its analogs at the frog muscle end-plate. J Physiol (Lond) 369:501-557.

Concas A, Santoro G, Serra M, Sanna E, Biggo G (1991) Neurochemical action of the general anaesthetic propofol on the chloride ion channel coupled with GABA A $_{\mathrm{A}}$ receptors. Brain Res 542:225-232.

Forscher P, Oxford GS (1985) Modulation of calcium channels by norepinephrine in internally dialyzed avian sensory neurons. J Neurochem 42:1-11.

Franke C, Parnas H, Hovav G, Dudel J (1993) A molecular scheme for the reaction between acetylcholine and nicotinic channels. Biophys J 64:339-356.

Frenkel C, Urban BW (1991) Human brain sodium channels as one of the molecular target sites for the new intravenous anaesthetic propofol (2,6-diisopropylphenol). Eur J Pharmacol 208:75-79.

Frosch MP, Lipton SA, Dichter MA (1992) Desensitization of GABAactivated currents and channels in cultured cortical neurons. J Neurosci 12:3042-3053.

Gage PW, Robertson B (1985) Prolongation of inhibitory postsynaptic currents by pentobarbitone, halothane and ketamine in CAl pyramidal cells in rat hippocampus. Br $J$ Pharmacol 85:675-681.

Hablitz JJ (1992) Voltage-dependence of $\mathrm{GABA}_{\mathrm{A}}$-receptor desensitization in cultured chick cerebral neurons. Synapse 12:169-171.

Hales TG, Lambert JJ (1992) The actions of propofol on inhibitory amino acid receptors of bovine adrenomedullary chromaffin cells and rodent central neurones. Br J Pharmacol 104:621-628.

Hara M, Yoshihisa K, Ikemoto Y (1993) Propofol activates GABA receptor-chloride ionophore complex in dissociated hippocampal pyramidal neurons of the rat. Anesthesiology 79:781-788.

Ikemoto Y, Akaike N, Kijima H (1988) Kinetic and pharmacological properties of the GABA-induced chloride current in Aplysia neurones: a 'concentration clamp' study. Br J Pharmacol 95:883-895.

MacDonald JF, Mody I, Salter MW (1989) Regulation of $N$-methyl$\mathrm{D}$-aspartate receptors revealed by intracellular dialysis of murine neurones in culture. J Physiol (Lond) 414:17-34.

Macdonald RL, Rogers CJ, Twyman RE (1989) Barbiturate regulation of kinetic properties of the $\mathrm{GABA}_{\mathrm{A}}$ receptor channel of mouse spinal neurones in culture. J Physiol (Lond) 417:483-500.

Magnelli V, Nobile M, Maestrone E (1992) $\mathrm{K}^{+}$Channels in PC12 cells are affected by propofol. Eur J Physiol 420:393-398.

Mienville J-M, Vicini S (1989) Pregnanalone sulfate antagonizes GA$\mathrm{BA}_{\mathrm{A}}$ receptor-mediated currents via a reduction of channel opening frequency. Brain Res 49:190-194.

Mierlak D, Farb DH (1988) Modulation of neurotransmitter receptor desensitization: chlordiazepoxide stimulates fading of the GABA response. J Neurosci 8:814-820.

Oh DJ, Dichter MA (1992) Desensitization of GABA-induced currents in cultured rat hippocampal neurons. Neuroscience 49:571-576.

Orser B (1994) Propofol-induced neuroexcitation and receptor desensitization. Can J Anaesth 41:366-371.

Orser B, Wang L-Y, MacDonald JF (1993a) Propofol modulates GA$\mathrm{BA}_{\mathrm{A}}$ channel desensitization. Proc IUPS XXXII 204:42.

Orser BA, Wang L-Y, MacDonald JF (1993b) Propofol modulates the single-channel kinetic properties of $\mathrm{GABA}_{\mathrm{A}}$ receptor channels. Can J Anaesth 40:5(11)A15.

Orser BA, Bertlik M, MacDonald JF (1993c) Propofol (2,6 di-isopropylphenol) inhibits NMDA-activated currents In hippocampal neurons. Soc Neurosci Abstr 19:296.9.
Otis TS, Mody I (1992) Modulation of decay kinetics and frequency of $\mathrm{GABA}_{\mathrm{A}}$ receptor-mediated spontaneous inhibitory postsynaptic currents in hippocampal neurons. Neuroscience 49:13-32.

Ozawa S, Yuzaki M (1984) Patch-clamp studies of chloride channels activated by gamma-aminobutyric acid in cultured hippocampal neurons of the rat. Neurosci Res 1:275-293.

Pearce RA (1993) Physiological evidence for two distinct GABA responses in rat hippocampus. Neuron 10:189-200.

Pennefather P, Quastel DM (1982) Fast desensitization of the nicotinic receptor at the mouse neuromuscular junction. Br $\mathrm{J}$ Pharmacol 77: 395-404.

Pennefather P, Puil E, Quastel DMJ (1980) Steroid anaesthetics: inhibition of depolarization-secretion coupling at the mouse motor nerve terminal. Can J Physiol Pharmacol 58:1221-1228.

Rics CR, Scoates PJ, Puil E (1994) Opisthotonis following propofol: a nonepileptic perspective and treatment strategy. Can J Anaesth 41: 414-419.

Robertson B (1989) Actions of anaesthetics and avermectin on GA$\mathrm{BA}_{\mathrm{A}}$ chloride channels in mammalian dorsal root ganglion neurones. $\mathrm{Br} J$ Pharmacol 98:167-176.

Sather W, Dieudonne S, MacDonald JF, Ascher P (1992) Activation and desensitization of $N$-methyl-D-aspartate receptors in nucleated outside-out patches from mouse neurones. J Physiol (Lond) 450:643672.

Shafer A, Van A, Doze BS, Shafer SL, White PF, (1988) Pharmacokinetics and pharmacodynamics of propofol infusions during general anesthesia. Anesthesiology 69:348-356.

Sieghart W (1992) $\mathrm{GABA}_{\mathrm{A}}$ receptors: ligand-gated $\mathrm{Cl}^{-}$ion channels modulated by multiple drug-binding sites. Trends Neurosci 13:446450.

Sigel E, Baur R (1988) Allosteric modulation by benzodiazepine receptor ligands of the $\mathrm{GABA}_{\mathrm{A}}$ receptor channel expressed in Xenopus Oocytes. J Neurosci 8:289-295.

Silvilotti L, Nistri A (1991) GABA receptor mechanisms in the central nervous system. Prog Neurobiol 36:35-92.

Sneyd JR (1992) Excitatory events associated with propofol anaesthesia: a review. J R Soc Med 85:288-291.

Twyman RE, Madonald RL (1992) Neurosteroid regulation of GABA receptor single-channel kinetic properties of mouse spinal cord neurones in culture. J Physiol (Lond) 456:215-245.

Valeyev AY, Cruciani RA, Lange GD, Smallwood VS, Barker JJ (1993) $\mathrm{Cl}^{-}$channels are randomly activated by continuous GABA secretion in cultured embryonic rat hippocampal neurons. Neurosci Lett 155: 199-203.

Vicini S, Mienville J-M Costa E (1987) Actions of benzodiazepine and $\beta$-carboline derivatives on $\gamma$-aminobutyric acid-activated $\mathrm{Cl}^{-}$ channels recorded from membrane patches of neonatal rat cortical neurons in culture. J Pharmacol Exp Ther 243:1195-1201.

Wachtel RE, Wegrzynowics ES (1992) Kinetics of nicotinic acetylcholine ion channels in the presence of intravenous anaesthetics and induction agents. Br J Pharmacol 106:623-627.

Weiss DS (1988) Membrane potential modulates the activation of GABA-gated channels. J Neurophysiol 59:514-527.

Weiss DS, Magelby KL (1989) Gating scheme for single GABA-activated $\mathrm{Cl}^{-}$channels determined from stability plots, dwell-times distributions, and adjacent-interval durations. J Neurosci 9:13141324.

Weiss DS, Barnes EM, Hablitz JJ (1988) Whole-cell and single-channel recordings GABA-gated currents in cultured chick cerebral neurones. J Neurophysiol 59:495-513. 